\title{
Seismic Protection of Cabinet Stored Cultural Relics with Silicone Dampers
}

\author{
Xiaoqing Ning $\mathbb{D}$, Junwu Dai $\mathbb{D}$, Wen Bai $\mathbb{D}$, Yongqiang Yang $\mathbb{D}$, and Lulu Zhang
}

Key Laboratory of Earthquake Engineering and Engineering Vibration, Institute of Engineering Mechanics, China Earthquake Administration, Harbin 150080, China

Correspondence should be addressed to Junwu Dai; jwdai@iem.cn

Received 23 January 2018; Accepted 8 April 2018; Published 15 May 2018

Academic Editor: Matteo Filippi

Copyright (C) 2018 Xiaoqing Ning et al. This is an open access article distributed under the Creative Commons Attribution License, which permits unrestricted use, distribution, and reproduction in any medium, provided the original work is properly cited.

Cultural relics are precious properties of all humankind, the damage of which is nonresilient. In previous earthquakes, stored cultural relics have shown poor seismic performance, so effective seismic methods are urgently needed. However, due to various restrictions, traditional damping methods are not suitable for the cultural relics stored in the Palace Museum. An efficient damping method, composed of silicone damper and connecting elements, is proposed to protect these stored cultural relics. This novel damping device is very convenient to install and no change or move for the original structures is needed. It is suitable for various kinds of new and existing relic cabinets. In order to validate the effectiveness of this novel damping method, both numerical simulation and shaking table tests are carried out. Results show that this method can effectively enhance the seismic performance of relic cabinet itself and the internal cultural relics. Relic cabinets with damping devices deform significantly less than noncontrol cabinets while the inside relics also have less sliding or overturning. Overall, a damping method, designed for seismic protection of cabinet stored cultural relics, is proposed and its effectiveness has been successfully demonstrated.

\section{Introduction}

Situated in the heart of Beijing, the Palace Museum is one of the most prestigious museums in China and the world at large. Over 1.8 million pieces of cultural relics are stored in the Palace Museum, including paintings, calligraphy, ceramics, and antiquities of the imperial collections, which are priceless treasures to all humankind. Relics in museum are either being displayed or stored in storehouse. For better display effect and easier access, relics under both circumstances are typically unanchored. Stored relics, such as porcelains and jadeites, are typically stored in floating cabinets. Most of these relic cabinets lack proper seismic protection measures. Because of these relics' high value, fragility, and nonreproducibility, once strong earthquakes happen, the adverse consequences would be tremendous and unacceptable [1]. The 1994 LA earthquake, the 1995 Kobe earthquake, and the 1999 Chichi earthquake have all caused irreversible damage to relics. Cabinet stored relics tend to slide and collapse corresponding to their support and are easy to collide among each other during earthquakes. During the 2008 Wenchuan earthquake, more than 4,000 pieces of relics were damaged and 200 of them were rare ones. Cabinet stored relics perform even worse than those displayed (Figure 1). Generally, reasons of relic's damage can be concluded as follows: (1) collapse of building structure; (2) excessive vibration of supporting shelves inducing sliding and collapse; (3) failure of nonstructural components; (4) vulnerability of relic itself; and (5) secondary disasters [2].

Finding proper methods to protect relics is important and inevitable [3-16]. Traditional methods include (1) lowering the center of gravity, (2) anchorage of the relic bottom, and (3) cable fixation. Besides traditional methods, base isolation and damping control methods are also used for relic protection. Base isolation is an effective method at reducing earthquake responses, and it is mostly used to protect display relics. However, for stored relics, this method seems not very suitable, as base isolation may bring excessive displacement that the storehouse has no enough space to accommodate, and the installation of base isolation will inevitably result in movement of the existing cabinets and relics inside, which should better be significantly avoided. As for damping control 

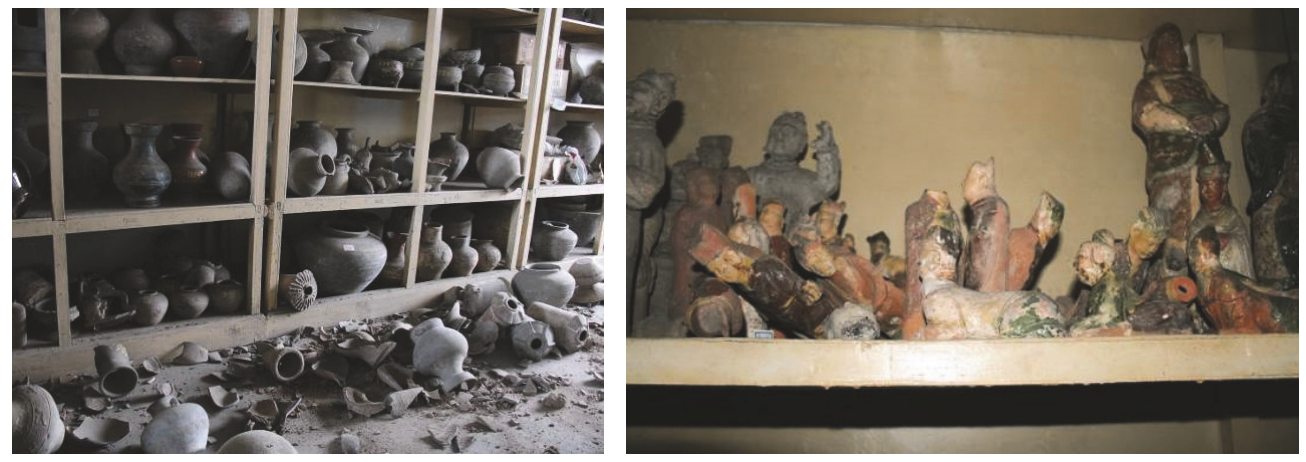

FIGURE 1: Damage of cabinet stored relics in Wenchuan earthquake.

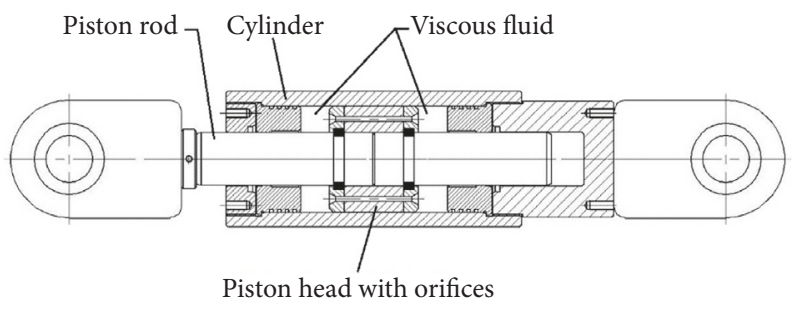

FIGURE 2: Basic construction of viscous damper.

method, it may be a suitable and effective way to be used for stored relics protection. There are also some requirements to be satisfied when it is used in the relic storehouse; that is, the installation of damping control system should be fast, convenient, and environmentally friendly, and the use of damping system should not affect the relics.

Based on the above reasons, a damping control system based on viscous dampers is advocated. Cabinets are connected to each other at the top through viscous dampers and connecting elements. No move or change of the cabinets as well as the inside relics is needed. Besides, this damping system is fast and convenient to install and is environmental friendly.

In order to validate the effectiveness and robustness of this damping method, shaking table tests and finite element analyses are carried out. The design and configuration of damping system are given in Section 2. Information about relic cabinets is given in Section 3. Numerical modeling, seismic input, and parameter optimization are presented in Section 4. Shaking table tests are conducted in Section 5. Conclusions are listed in Section 6.

\section{Damping System}

2.1. Viscous Dampers. Viscous damper is developed based on the principle of fluid motion, especially the throttling resistance produced when the fluid gets through the throttling orifice, which is associated with the piston motion velocity. Viscous damper is widely used in high-rise buildings, bridges, seismic retrofitting of building structures, vibration resistance of industrial pipeline equipment, and military industry [16, 18-21].
Viscous damper is usually composed of cylinder, piston, viscous fluid, and guide rod, the basic construction of which is shown in Figure 2. Its working principle is to convert the vibration energy into heat energy through the relative motion between the molecules of viscous fluid, thus reducing the vibration response of the structure. The characteristic is that the damping force is proportional to the velocity and the damping force is zero when the velocity is zero. Therefore, viscous damper can reduce both structural stress and displacement in seismic response.

In practical application, the mechanical characteristic of viscous damper is decided by viscous fluid property and damper construction. General expression of damping force is seen in (1), where $F$ is damping force, $C$ is damping coefficient, $V$ is piston velocity, and $\theta$ is velocity index. Velocity index can be designated according to the engineering needs, general value of which is between 0.01 and 1 . Based on the force-displacement curve of viscous damper, the smaller the velocity index, the closer the curve shape from ellipse to rectangle, the greater the energy dissipation capacity of the damper [21].

$$
F=C V^{\theta}
$$

For cultural relics stored in cabinets, the preservation conditions such as the humidity and temperature environment of the storehouse are extremely strict, which must be satisfied with the specific requirements. Therefore, the damper used in storehouse must ensure two aspects: (1) damper should has good durability, which means damper cannot damage and can keep working status for a long time; (2) damper should not produce toxic or harmful gases and liquids, to avoid environment pollution inside storehouse 

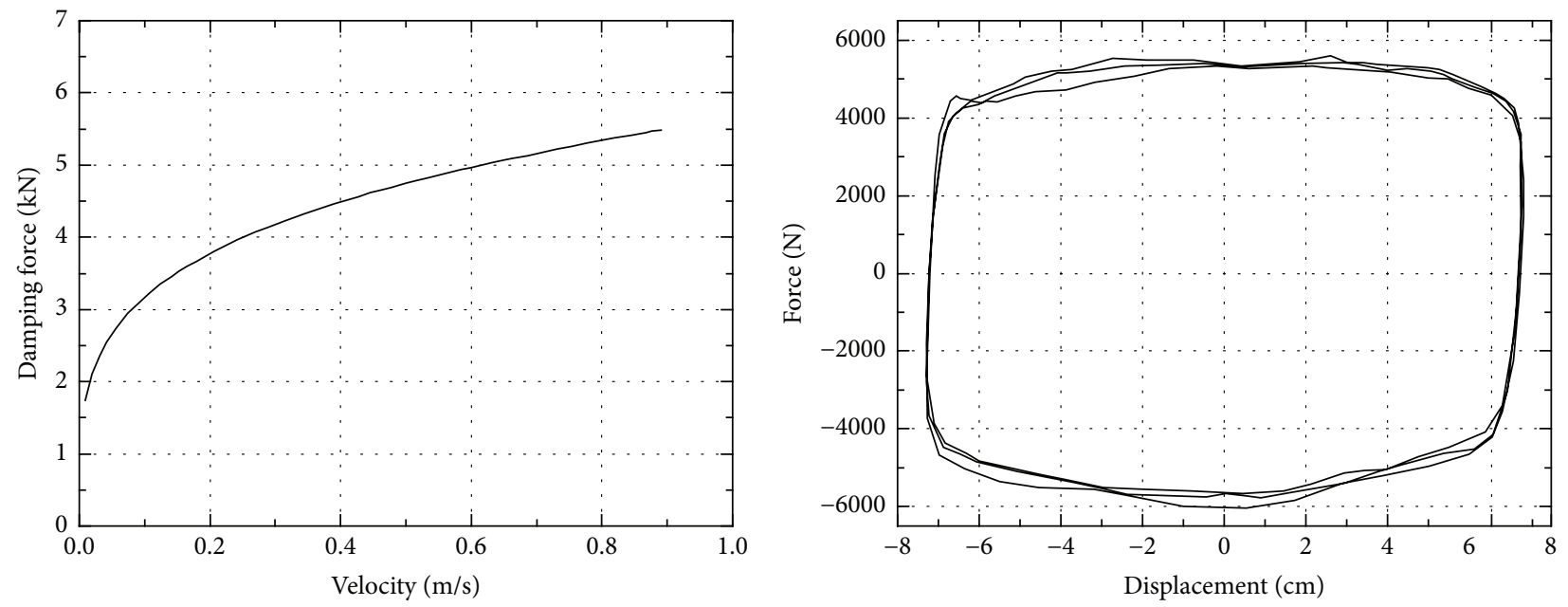

(a) Damper I
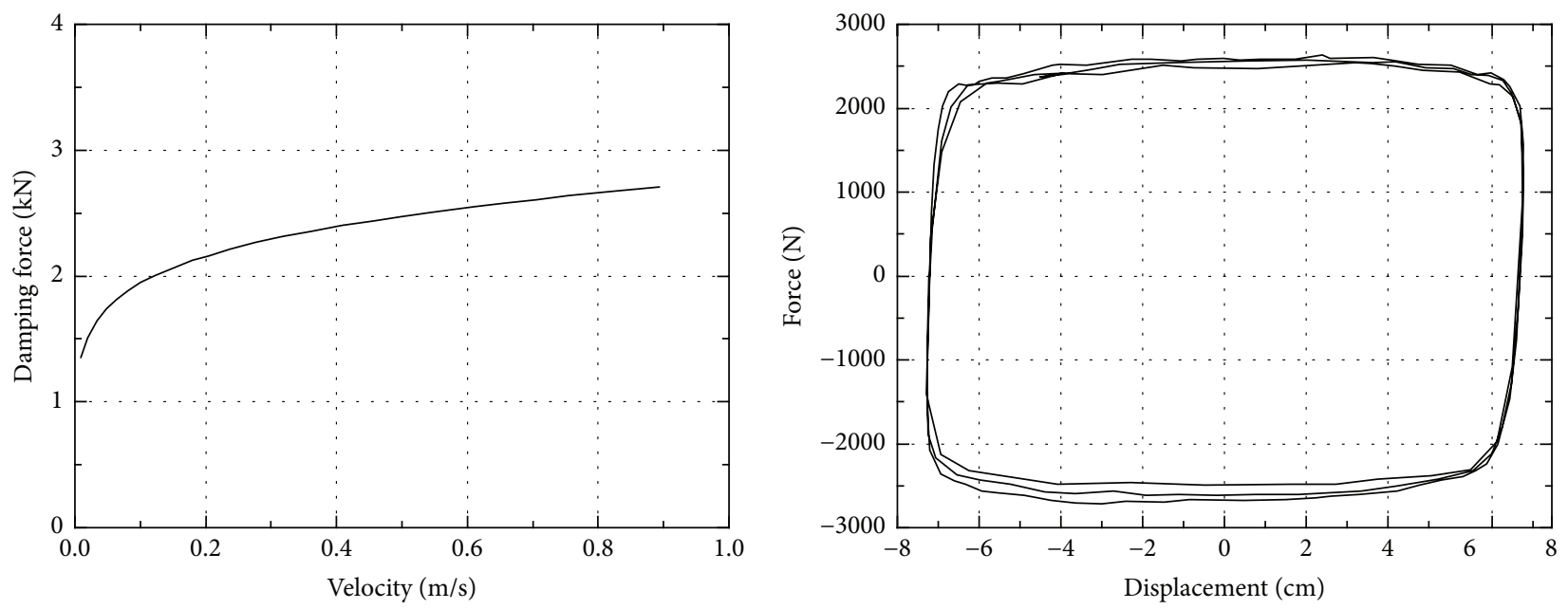

(b) Damper II

FIGURE 3: Force-velocity curves and force-displacement curves (under the max velocity) of silicone dampers [17].

which may cause damage of cultural relics. The common types of viscous dampers applied in engineering include air damper, liquid damper, and silicone damper. The lifetime of air damper is only $3-5$ years with high maintenance cost. The liquid damper is easy to leak and contaminate storehouse environment. The silicone damper uses environmental protection material and has good durability and energy dissipation characteristics. Therefore, the silicone damper is selected for the design of damping device used in relic cabinets.

There are two configurations of silicone damper chosen in the damping device, named damper I and damper II [17]. The maximum force of damper I and damper II is $5.5 \mathrm{kN}$ and $2.7 \mathrm{kN}$, respectively. The specifications of silicone dampers are shown in Table 1, while the force-velocity curves and forcedisplacement curves (when velocity is the $\max 0.90 \mathrm{~m} / \mathrm{s}$ ) are shown in Figure 3.

2.2. Connecting Elements. In the design of connecting elements, the following requirements need to be satisfied: (1)
TABLE 1: Specifications of silicone dampers [17].

\begin{tabular}{lcc}
\hline Parameters & Damper I & Damper II \\
\hline Damper configuration & Double acting & Double acting \\
Damping mechanism & Viscous fluid & Viscous fluid \\
Characteristic equation & $F=C V^{\theta}$ & $F=C V^{\theta}$ \\
Damping factor $C$ & $5.65 \mathrm{kN}(\mathrm{s} / \mathrm{m})^{\theta}$ & $2.75 \mathrm{kN}(\mathrm{s} / \mathrm{m})^{\theta}$ \\
Velocity index $\theta$ & 0.25 & 0.15 \\
Max force & $5.5 \mathrm{kN}$ & $2.7 \mathrm{kN}$ \\
Nominal design frequency & $2.0 \mathrm{~Hz}$ & $2.0 \mathrm{~Hz}$ \\
Max piston velocity & $0.90 \mathrm{~m} / \mathrm{s}$ & $0.90 \mathrm{~m} / \mathrm{s}$ \\
Total stroke & $212 \mathrm{~mm}$ & $212 \mathrm{~mm}$ \\
\hline
\end{tabular}

no movement of relic cabinet; (2) no use of measures that may damage relic cabinet, such as punching and using glue; (3) using modular assembly method; and (4) simple and quick construction, to reduce interference to the storehouse environment. 

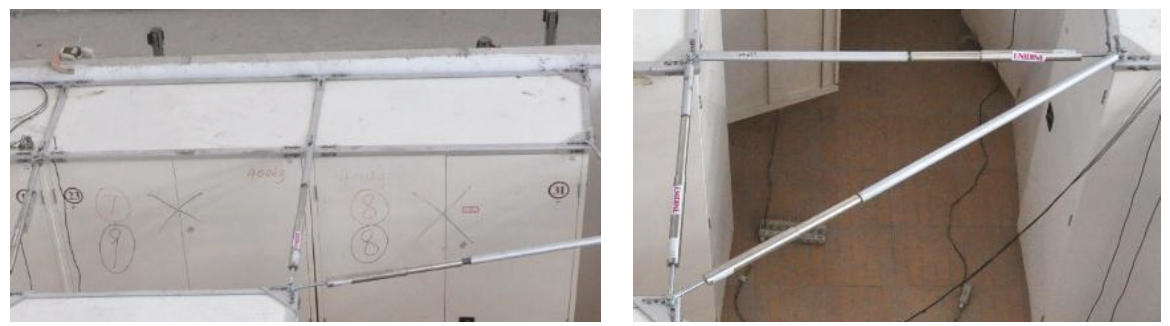

FIgURE 4: Assembled damping device.
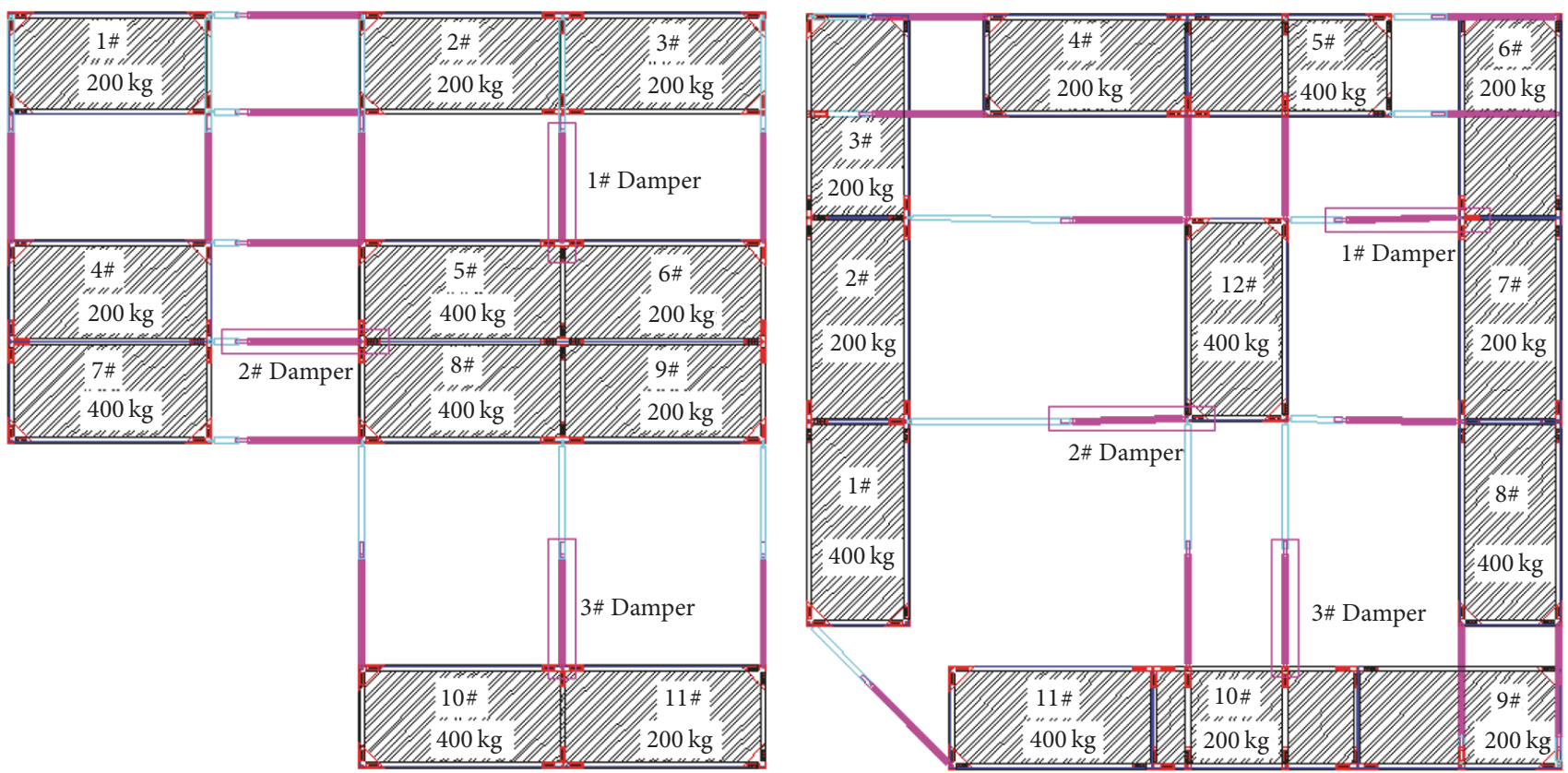

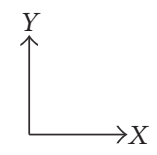

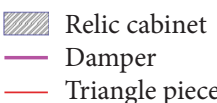

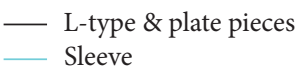

(a)

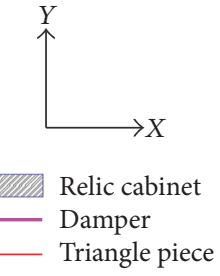

— Triangle piece

Figure 5: Two typical layouts of relic cabinets ((a) layout A, (b) layout B).

The designed connecting elements are made up by six kinds of components: triangle piece, T-type piece, cross-type piece, L-type piece, plate piece, and sleeve. As the spaces between relic cabinets are different, while the length of the damper is fixed, the connection requirements between cabinets can be met by designing and changing the length of the sleeve. The damping device assembled by the silicone dampers and connecting elements is shown in Figure 4.

\section{Relic Cabinets}

Through the inspection of storerooms in the Palace Museum, two typical layouts of relic cabinets are selected, named layout A and layout B, respectively (Figure 5). Layout A has totally 11 relic cabinets and 13 dampers, with the arrangement that the short sides of most cabinets are against the wall. Correspondingly, layout B has totally 12 relic cabinets and 15 dampers, with the arrangement that the long sides of most cabinets are against the wall. The length, width, and height sizes of each cabinet are $1200 \mathrm{~mm} \times 600 \mathrm{~mm} \times 2000 \mathrm{~mm}$. The total sizes of two layout models in $X, Y, Z$ directions are both $4500 \mathrm{~mm} \times 4500 \mathrm{~mm} \times 2000 \mathrm{~mm}$. Due to the actual situation that the types and numbers of cultural relics stored in one cabinet are usually different from those stored in other cabinets, the additional weight put in each cabinet is set to $200 \mathrm{~kg}$ and $400 \mathrm{~kg}$ separately. 


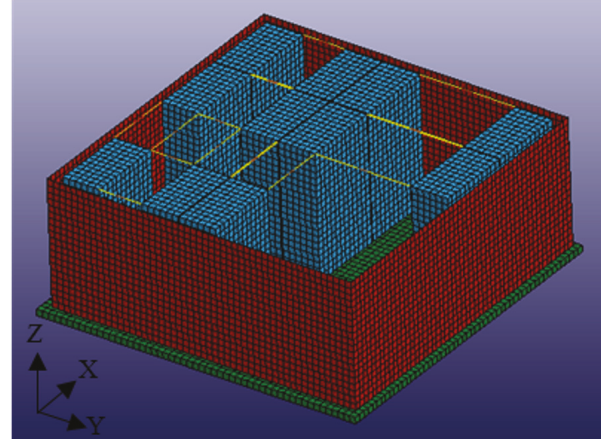

(a)

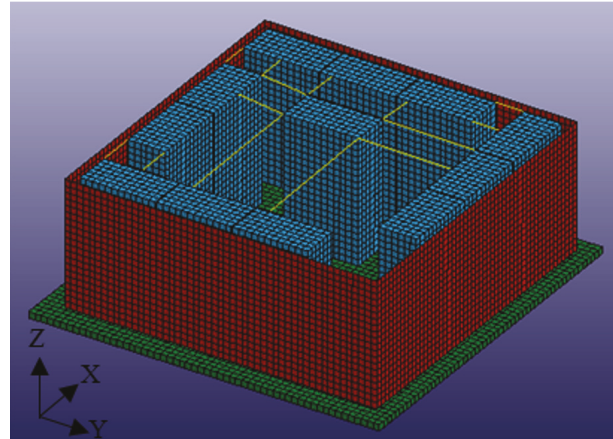

(b)

Figure 6: Numerical models of relic cabinets ((a) layout A, (b) layout B).

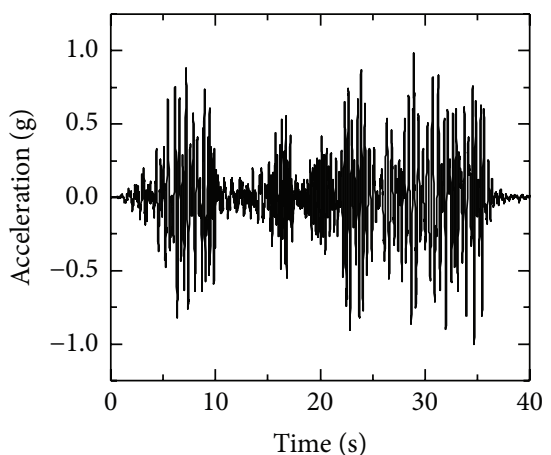

— Synthetic motion- $X$

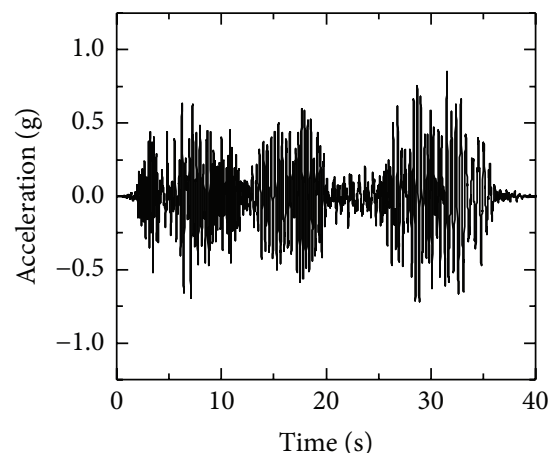

- Synthetic motion-Y

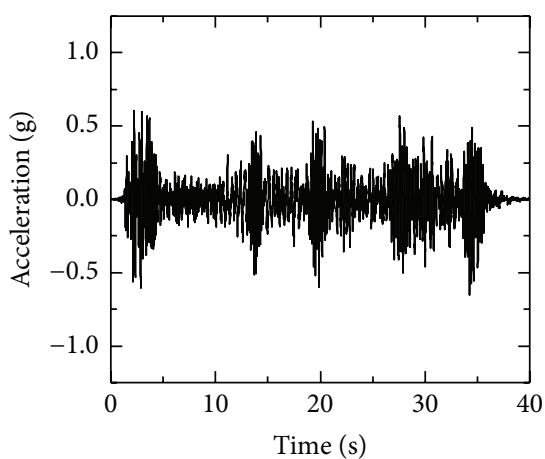

- Synthetic motion- $Z$

Figure 7: Synthetic ground motion.

\section{Numerical Simulation of the Protected Relic Cabinets}

The numerical simulation of relic cabinets is conducted with finite element software ANSYS/LS DYNA. In order to study the seismic performance of the damping device, both the original cabinet model without any control measure and the model with damping device control are simulated. The dynamic time history responses of the models with and without control are both analyzed and compared. In addition, by comparing the damping effects of models that use different parameters of the damping device, the optimal parameters of the damper are designated.

4.1. Numerical Modeling. In the finite element model, relic cabinet is simulated by shell element, damper is simulated by spring-damping element, connecting element is simulated by three-dimensional beam element, and the ground and wall are simulated by solid element. The connection of relic cabinet and damper is simplified as a hinge joint, and the connection of damper and sleeve is set rigid. According to the parameters of the actual dampers, the damping factor is $5.0 \mathrm{kN}(\mathrm{s} / \mathrm{m})^{\theta}$, and the velocity index is 0.2 . Frictional contact is defined between the bottom of relic cabinet (metal material) and the ground (brick material), with the static friction coefficient 0.2 and the kinetic friction coefficient 0.16 , in accordance with the measured value of storehouse in the Palace Museum. The central difference explicit integration scheme is used in numerical analysis. The numerical models of the relic cabinets in two layouts are shown in Figure 6.

4.2. Seismic Inputs. According to the site condition in the area where the Palace Museum is located, referring to China's code for seismic design of buildings (GB50011-2010) [22], three groups of three-dimensional ground motions are selected for the numerical analyses and shaking table tests: (1) synthetic ground motion; (2) Beijing hotel ground motion in Tangshan earthquake; and (3) Wolong ground motion in Wenchuan earthquake. The time history curves of ground motions are shown in Figures 7-9, and the normalizing response spectra are shown in Figure 10, which can envelope the design spectrum in the short period range through increasing inputs. According to the seismic code, the ground motion inputs are classified into three levels. The peak ground accelerations (PGA) of the three levels in $x$ direction are, respectively, $0.20 \mathrm{~g}, 0.40 \mathrm{~g}$, and $0.62 \mathrm{~g}$, and the PGA input proportion of the three directions is $x: y: z=1: 0.85: 0.65$; the specific seismic input levels are shown in Table 2. 


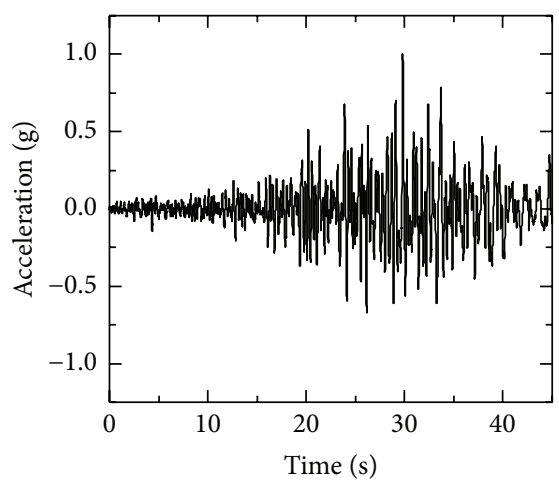

- Tangshan- $X$
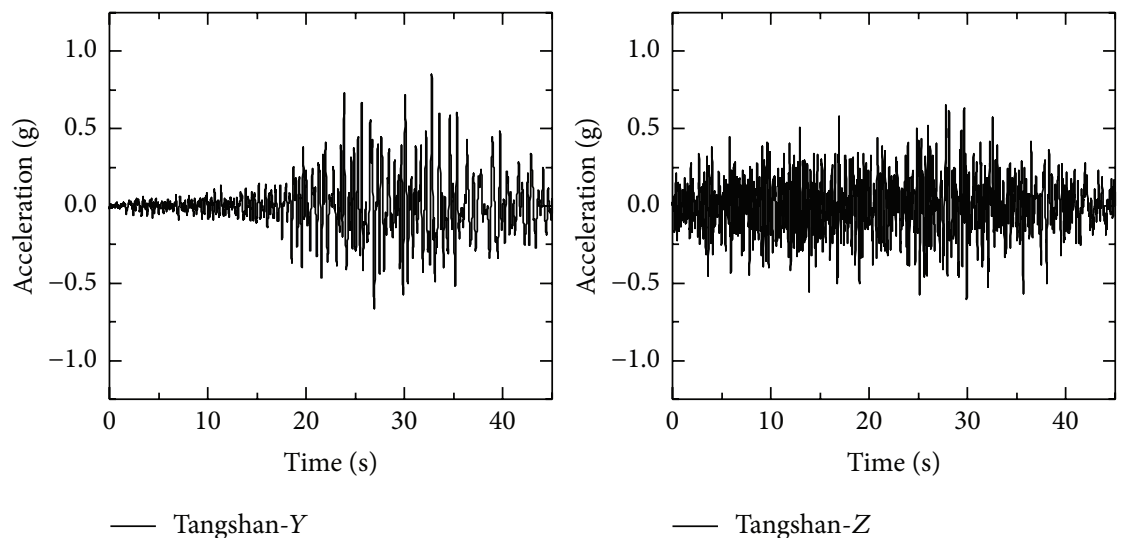

FIGURE 8: Beijing hotel ground motion in Tangshan earthquake.

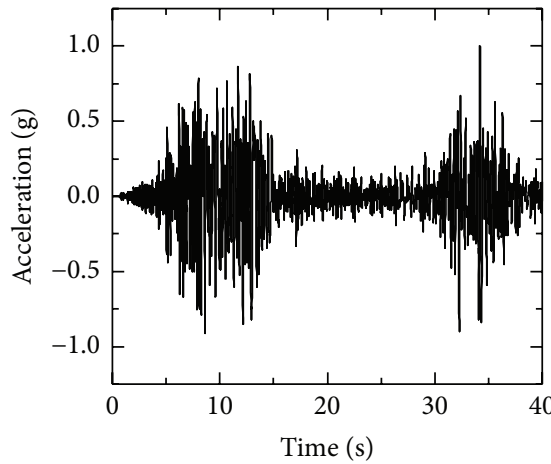

- Wenchuan- $X$

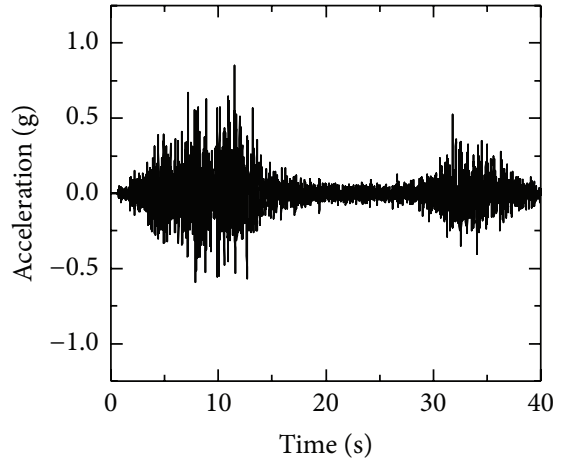

Wenchuan- $Y$

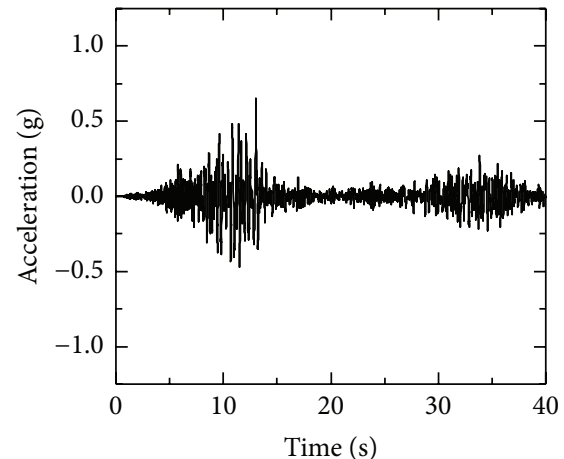

Wenchuan- $Z$

FIgURE 9: Wolong ground motion in Wenchuan earthquake.
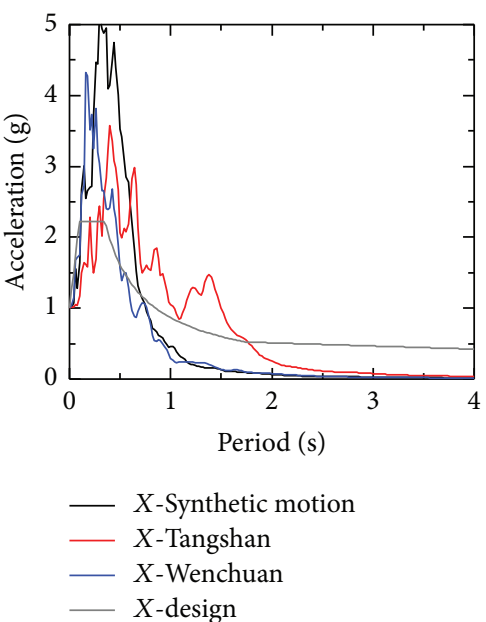
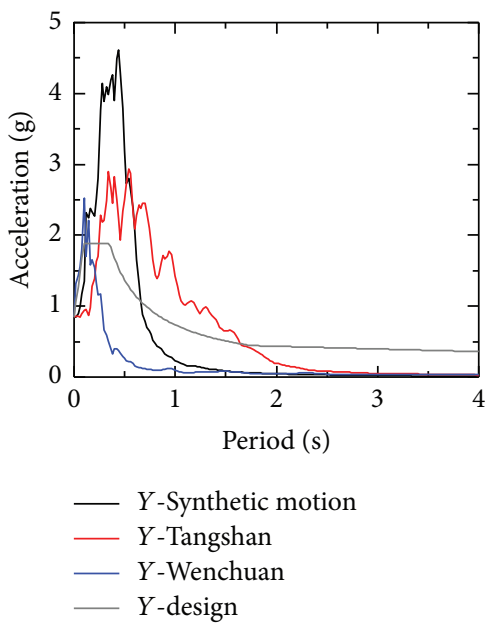

FIGURE 10: Response spectra.

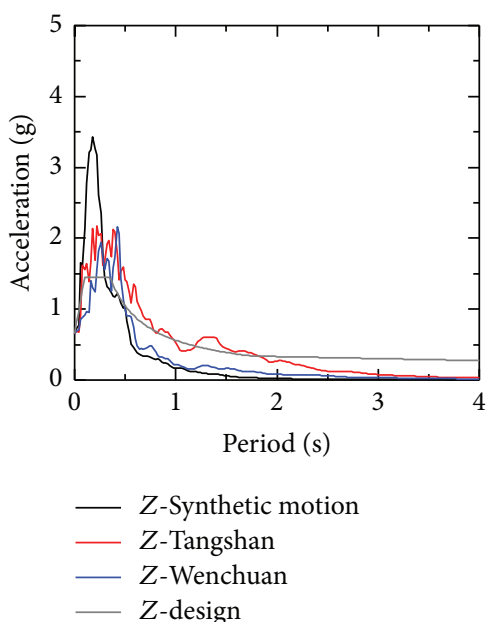

4.3. Dampers Parameters Optimization. Through the finite element calculation, the acceleration and displacement results of the top of cabinets and the force and displacement results of the dampers are obtained, in order to analyze the seismic performance of the damping device and adjust the appropriate parameters of the dampers. The damping ratio is defined as the indicator to evaluate the damping effect, calculated by (2), where $\alpha$ is the acceleration damping ratio, $a_{0}$ is the peak acceleration of the cabinet top without control, and $a_{1}$ is the peak acceleration of the cabinet top with damping control; $\beta$ is the displacement damping ratio, $d_{0}$ is the maximum displacement of the cabinet top without control 

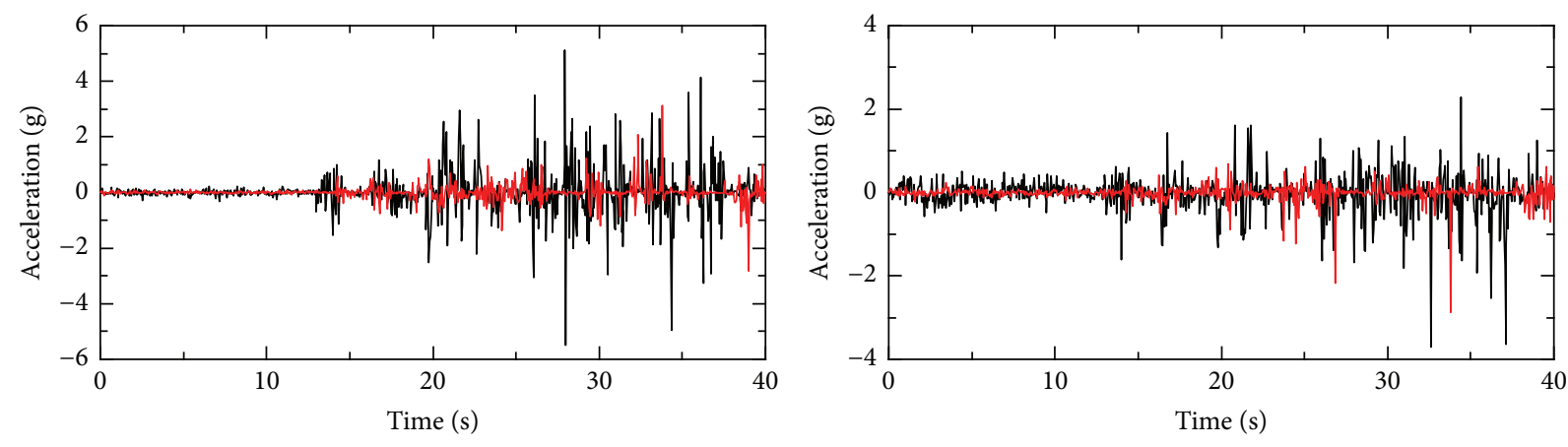

- X-Without control

— X-With control

- Y-Without control

- Y-With control

Figure 11: Acceleration time history curves of 4\# cabinet in layout A-T05 (0.40 g) (numerical).

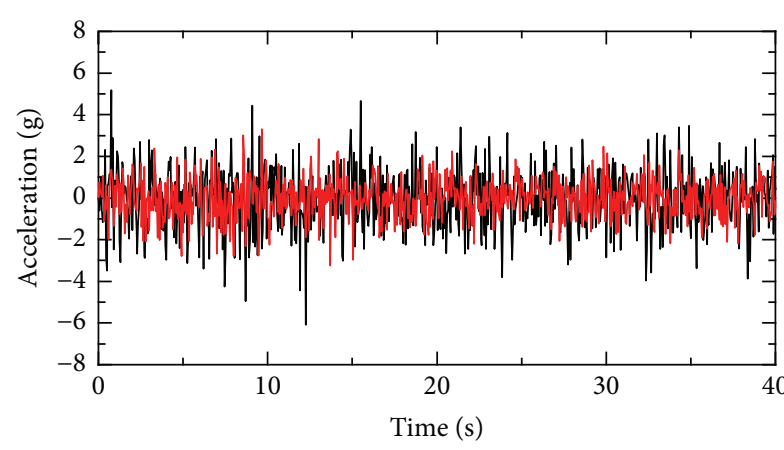

- X-Without control

— X-With control

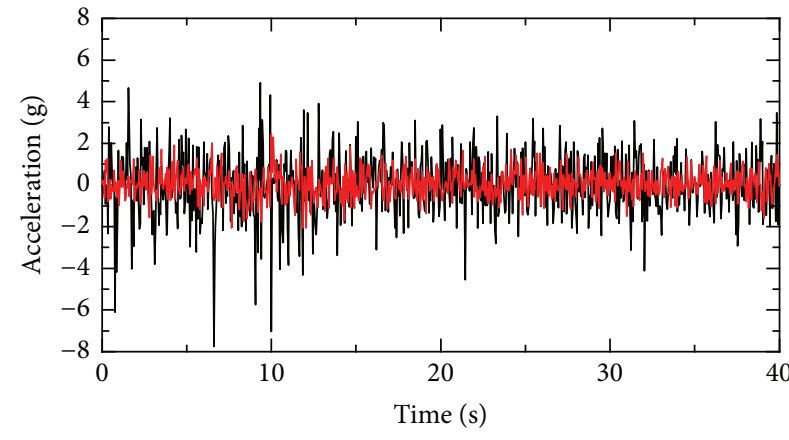

- Y-Without control

- Y-With control

FIGURE 12: Acceleration time history curves of 12\# cabinet in layout B-T09 (0.62 g) (numerical).

TABLE 2: Input levels.

\begin{tabular}{|c|c|c|c|c|}
\hline Name & Ground motions & \multicolumn{3}{|c|}{ Input PGA/g } \\
\hline T01 & Synthetic motion & & & \\
\hline T02 & Tangshan & $X=0.20 \mathrm{~g}$ & $Y=0.17 \mathrm{~g}$ & $Z=0.13 \mathrm{~g}$ \\
\hline T03 & Wenchuan & & & \\
\hline T04 & Synthetic motion & & & \\
\hline T05 & Tangshan & $X=0.40 \mathrm{~g}$ & $Y=0.34 \mathrm{~g}$ & $Z=0.26 \mathrm{~g}$ \\
\hline T06 & Wenchuan & & & \\
\hline T07 & Synthetic motion & & & \\
\hline T08 & Tangshan & $X=0.62 \mathrm{~g}$ & $Y=0.53 \mathrm{~g}$ & $Z=0.40 \mathrm{~g}$ \\
\hline T09 & Wenchuan & & & \\
\hline
\end{tabular}

(relative to the input), and $d_{1}$ is the maximum displacement of the cabinet top with damping control (relative to the input).

$$
\begin{aligned}
& \alpha=\frac{a_{1}}{a_{0}}, \\
& \beta=\frac{d_{1}}{d_{0}} .
\end{aligned}
$$

Due to the limited paper space, only the $4 \#$ relic cabinet in layout A and the 12\# relic cabinet in layout B are taken as examples to illustrate the damping effect. The comparisons of acceleration time history curves of the relic cabinets with and without control are shown in Figures 11 and 12, and the peak acceleration, maximum relative displacement, and damping ratios are shown in Tables 3 and 4 . The force time history curves of the dampers are shown in Figure 13, taking the $1 \#$ damper in layout $\mathrm{A}$ and the 2\# damper in layout $\mathrm{B}$ as examples.

The results show that the optimal acceleration damping ratio is 0.56 and the average acceleration damping ratio is 0.67 ; the optimal displacement damping ratio is 0.22 and the average displacement damping ratio is 0.48 . The range of the damping force is about $1.3 \mathrm{kN}$ to $4.3 \mathrm{kN}$, and the maximum relative displacement of the damper is about $50 \mathrm{~mm}$. Therefore, the parameters of the damper can be designated as follows: damping index is 0.2 , damping force is $2.7 \mathrm{kN}-5.5 \mathrm{kN}$, and maximum stroke is $\pm 100 \mathrm{~mm}$.

Through further analysis of the results, the following conclusions can be summarized. (1) The designed damping device can effectively reduce the seismic response of the cabinets and improve the seismic safety of the inside relics. (2) The different layouts of the relic cabinets do have influence on the damping effect, as the damping effect of layout $\mathrm{A}$ is better than that of the layout B. (3) With the damping device control, after ground motions, all the relic cabinets have the tendency 


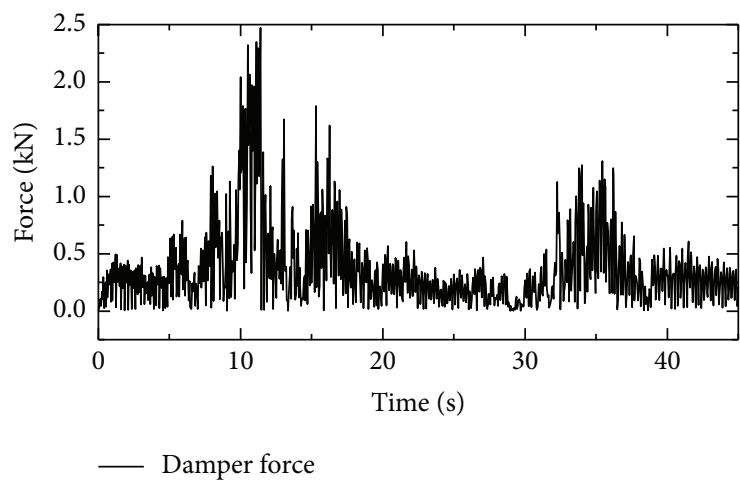

(a) 1\# damper in layout $\mathrm{A}$

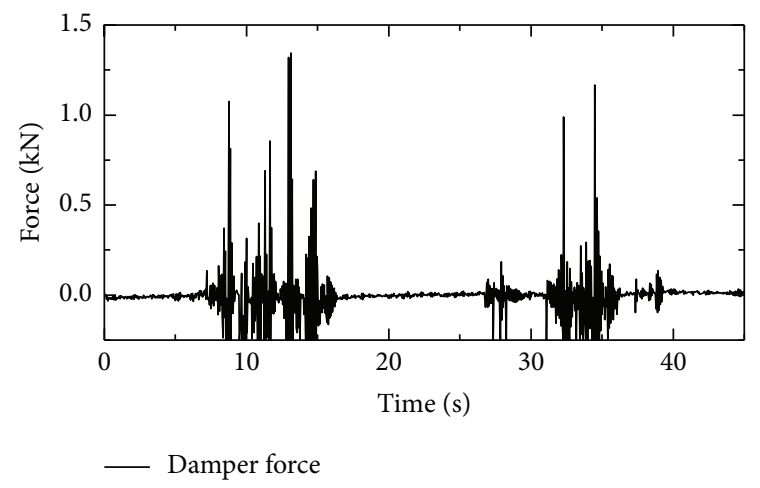

(b) 2\# damper in layout B

FIGURE 13: Force time history curves of the dampers (numerical).

TABLE 3: Peak acceleration (g) and acceleration damping ratio (numerical)

\begin{tabular}{|c|c|c|c|c|c|c|}
\hline \multirow[t]{2}{*}{ Input levels } & \multicolumn{3}{|c|}{$\begin{array}{l}\text { 4\# cabinet in } \\
\text { layout } A\end{array}$} & \multicolumn{3}{|c|}{$\begin{array}{l}\text { 12\# cabinet } \\
\text { in layout B }\end{array}$} \\
\hline & $X$ & $Y$ & $Z$ & $X$ & $Y$ & $Z$ \\
\hline \multicolumn{7}{|l|}{ T05 (0.40 g) } \\
\hline Without control $a_{0}$ & 1.97 & 1.93 & 2.00 & 2.29 & 2.19 & 2.40 \\
\hline With control $a_{1}$ & 1.28 & 1.33 & 1.32 & 1.59 & 1.69 & 1.44 \\
\hline Damping ratio $\alpha$ & 0.65 & 0.69 & 0.66 & 0.69 & 0.77 & 0.60 \\
\hline \multicolumn{7}{|l|}{ T06 $(0.40 \mathrm{~g})$} \\
\hline Without control $a_{0}$ & 2.00 & 1.90 & 1.90 & 2.59 & 2.26 & 2.27 \\
\hline With control $a_{1}$ & 1.40 & 1.25 & 1.24 & 1.46 & 1.45 & 1.58 \\
\hline Damping ratio $\alpha$ & 0.70 & 0.66 & 0.65 & 0.56 & 0.64 & 0.70 \\
\hline \multicolumn{7}{|l|}{ T08 (0.62 g) } \\
\hline Without control $a_{0}$ & 3.27 & 3.24 & 3.17 & 3.01 & 3.13 & 3.14 \\
\hline With control $a_{1}$ & 2.42 & 2.43 & 2.12 & 1.99 & 1.82 & 1.79 \\
\hline Damping ratio $\alpha$ & 0.74 & 0.75 & 0.67 & 0.66 & 0.58 & 0.57 \\
\hline \multicolumn{7}{|l|}{ T09 (0.62 g) } \\
\hline Without control $a_{0}$ & 3.26 & 3.14 & 2.98 & 2.96 & 3.22 & 3.08 \\
\hline With control $a_{1}$ & 2.25 & 2.42 & 2.21 & 1.81 & 1.90 & 2.03 \\
\hline Damping ratio $\alpha$ & 0.69 & 0.77 & 0.74 & 0.61 & 0.59 & 0.66 \\
\hline
\end{tabular}

to move towards the center of the storehouse. The integrity of the relic cabinets has been enhanced, effectively avoiding the collision between the relic cabinets and the wall and reducing the uncertainty of the stress state of the relic cabinets.

\section{Shaking Table Tests of the Protected Relic Cabinets}

5.1. Testing Mockup. In order to verify the actual damping effect of the damping device for the relic cabinets, the shaking table tests are carried out at the Key Laboratory of Earthquake Engineering and Engineering Vibration of China Earthquake Administration. The maximum load of the $5 \mathrm{~m} \times 5 \mathrm{~m}$ triaxial shaking table is $30 \mathrm{t}$, and the maximum accelerations under the full load are $2.04 \mathrm{~g}$ in $X$ and $Y$ directions and $2.3 \mathrm{~g}$ in $Z$ direction. The whole test models of the relic cabinets are
TABLE 4: Relative displacement ( $\mathrm{mm}$ ) and displacement damping ratio (numerical).

\begin{tabular}{lcccc}
\hline Input levels & \multicolumn{2}{c}{$\begin{array}{c}\text { 4 cabinet in } \\
\text { layout A }\end{array}$} & \multicolumn{2}{c}{ 12\# cabinet in } \\
& $X$ & $Y$ & $X$ & $Y$ \\
\hline T05 $(0.40 \mathrm{~g})$ & & & & \\
Without control $d_{0}$ & 30.10 & 14.10 & 8.04 & 20.30 \\
With control $d_{1}$ & 19.40 & 10.10 & 3.62 & 6.37 \\
Damping ratio $\beta$ & 0.64 & 0.72 & 0.45 & 0.31 \\
T06 (0.40 g) & & & & \\
Without control $d_{0}$ & 4.80 & 0.70 & 5.18 & 0.77 \\
With control $d_{1}$ & 3.10 & 0.50 & 2.33 & 0.47 \\
Damping ratio $\beta$ & 0.65 & 0.71 & 0.45 & 0.61 \\
T08 (0.62 g) & & & & \\
Without control $d_{0}$ & overturn & overturn & 24.80 & 32.50 \\
With control $d_{1}$ & 3.40 & 4.30 & 11.40 & 7.20 \\
Damping ratio $\beta$ & $/$ & $/$ & 0.46 & 0.22 \\
T09 (0.62 g) & & & & \\
Without control $d_{0}$ & 6.20 & 1.30 & 12.60 & 1.00 \\
With control $d_{1}$ & 4.00 & 0.90 & 2.60 & 1.00 \\
Damping ratio $\beta$ & 0.65 & 0.69 & 0.21 & 1.00 \\
\hline
\end{tabular}

shown in Figure 14. In the test, the parameters of the dampers are determined by the optimal parameters of the numerical simulation. Enough mass blocks are put inside each cabinet to add up the total weight. The whole cabinets are instrumented with accelerometers in three directions and displacement transducers in two directions in the top of cabinets, and the $1 \#, 2 \#$, and $3 \#$ dampers in both layout $A$ and $B$ (seen in Figure 5) are instrumented with load cells and displacement transducers. The seismic input conditions are consistent with Section 4.2.

\subsection{Test Results}

5.2.1. Test Phenomenon. As the test phenomenon can directly reflect the seismic damping effect, by observing the test 
TABLE 5: Peak accelerations (g) and acceleration damping ratios of 4\# cabinet in layout A (experimental).

\begin{tabular}{lcccc}
\hline Input levels & 4\# cabinet & $X$ & $Y$ & \\
\hline \multirow{3}{*}{ T02 $(0.20 \mathrm{~g})$} & Without control $a_{0}$ & 0.60 & 0.58 & 0.42 \\
& With control $a_{1}$ & 0.29 & 0.23 & 0.33 \\
& Damping ratio $\alpha$ & 0.48 & 0.40 & 0.78 \\
\hline \multirow{3}{*}{ T08 $(0.62 \mathrm{~g})$} & Without control $a_{0}$ & 2.02 & 2.44 & 1.26 \\
& With control $a_{1}$ & 1.71 & 0.52 & 0.08 \\
& Damping ratio $\alpha$ & 0.85 & 0.70 \\
\hline
\end{tabular}

TABLE 6: Relative displacements ( $\mathrm{mm}$ ) and displacement damping ratios of 12\# cabinet in layout B (experimental).

\begin{tabular}{lccr}
\hline Input levels & 12\# cabinet & $X$ & $Y$ \\
\hline \multirow{3}{*}{ T02 $(0.20 \mathrm{~g})$} & Without control $d_{0}$ & 13.38 & 14.53 \\
& With control $d_{1}$ & 1.69 & 0.66 \\
& Damping ratio $\beta$ & 0.13 & 0.05 \\
\hline \multirow{2}{*}{ T08 $(0.62 \mathrm{~g})$} & Without control $d_{0}$ & 273.96 & 79.61 \\
& With control $d_{1}$ & 40.41 & 13.06 \\
& Damping ratio $\beta$ & 0.15 & 0.16 \\
\hline
\end{tabular}

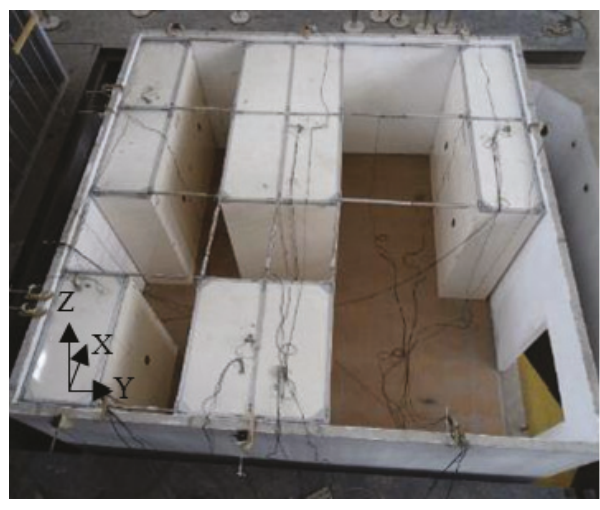

(a)

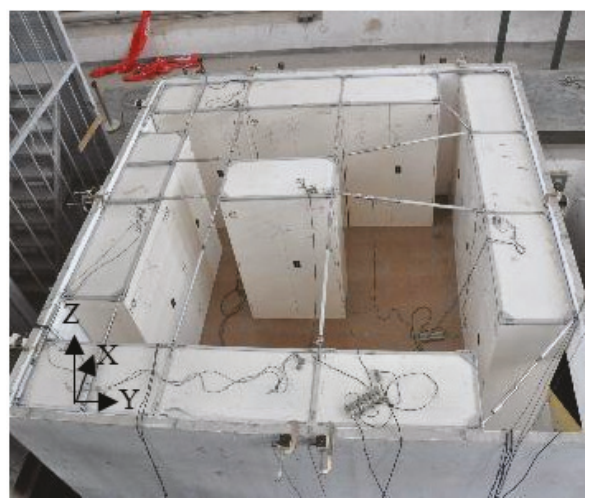

(b)

FIgURE 14: Text models ((a) layout A, (b) layout B).

phenomena of layout A and the layout B both without and with control (Figure 15), it can be summed up as follows.

In the cases without control, under PGA $0.20 \mathrm{~g}$ level, the slipping of relics in the cabinet is obvious; under PGA $0.40 \mathrm{~g}$ level, some cabinet doors are opened, the cabinet appears slipping, and the slipping of the relics is obvious; under PGA $0.62 \mathrm{~g}$ level, the cabinet doors are almost all opened, all cabinets slip obviously, and several cabinets collide with each other.

In the cases with control, under PGA $0.20 \mathrm{~g}$ level, there is nearly none slipping of the relics; under PGA $0.40 \mathrm{~g}$ level, the cabinet doors are locked well, the cabinets do not slip, and only the inside relics slip slightly; under PGA $0.62 \mathrm{~g}$ level, several cabinet doors are opened, and several cabinets slip slightly.

Compared to the two different layouts, it can be found that, in the cases without control, under the same level, the seismic damage of layout A (with the short sides of most relic cabinets being against the wall) is lighter, while the damage of layout B (with the long sides of most relic cabinets being against the wall) is heavier, with cabinet doors opening, cabinet sliding earlier, and collision between cabinets. In the cases with control, both of the two layouts have obvious damping effect, and the damping effect of layout $\mathrm{A}$ is better than that of layout B.

5.2.2. Acceleration Responses of Relic Cabinets. Taking the 4\# relic cabinet in layout A as an example, under T02 (0.20 g) and T08 (0.62 g) levels, the peak accelerations and acceleration damping ratios of $4 \#$ cabinet with and without control are shown in Table 5 , and the acceleration time history curves are shown in Figures 16 and 17.

5.2.3. Displacement Responses of Relic Cabinets. Taking the $12 \#$ relic cabinet in layout $\mathrm{B}$ as an example, under T02 $(0.20 \mathrm{~g})$ and T08 (0.62 g) levels, the displacements (relative to the input) and displacement damping ratios of 12 \# cabinet with and without control are shown in Table 6, and the 

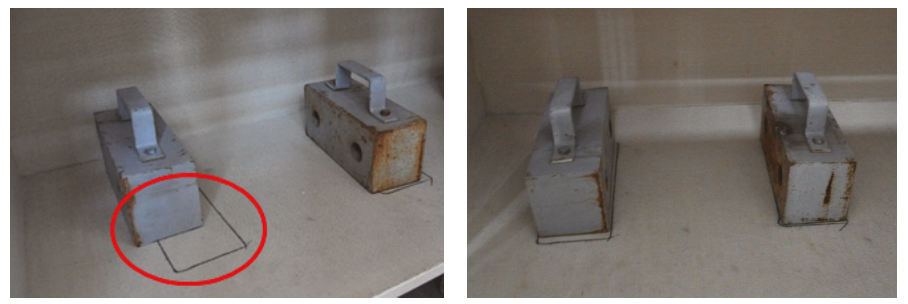

(a) Layout A-PGA $0.20 \mathrm{~g}$

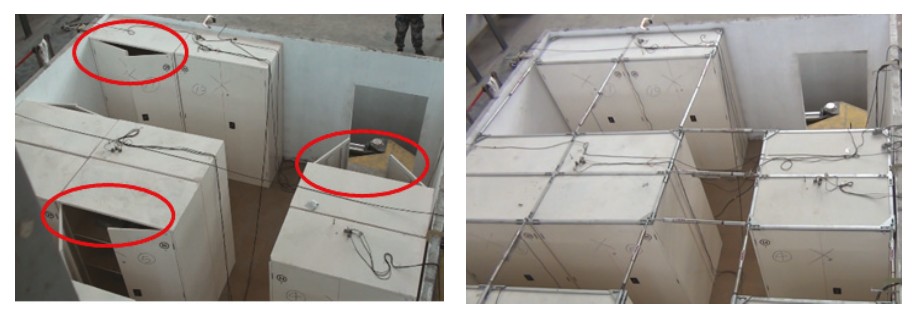

(b) Layout A-PGA $0.40 \mathrm{~g}$

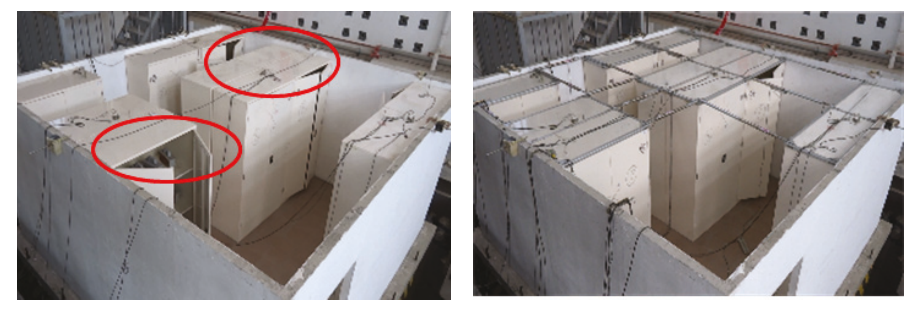

(c) Layout A-PGA $0.62 \mathrm{~g}$

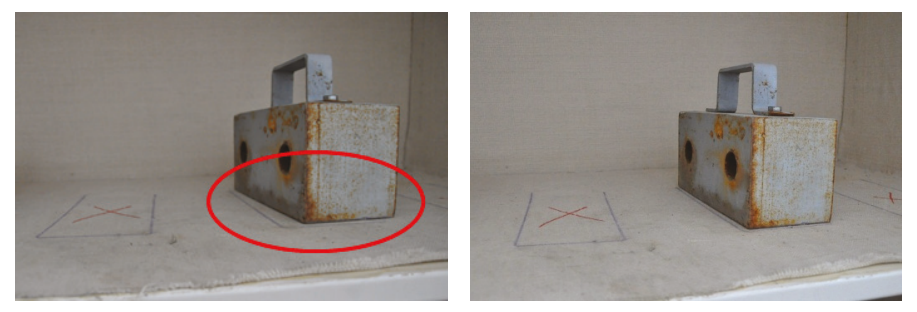

(d) Layout B-PGA $0.20 \mathrm{~g}$
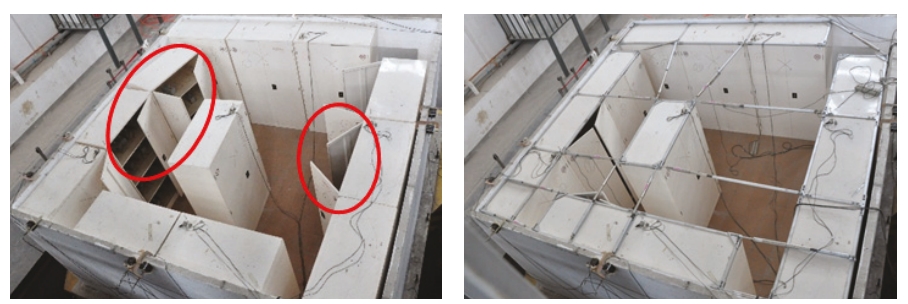

(e) Layout B-PGA $0.40 \mathrm{~g}$

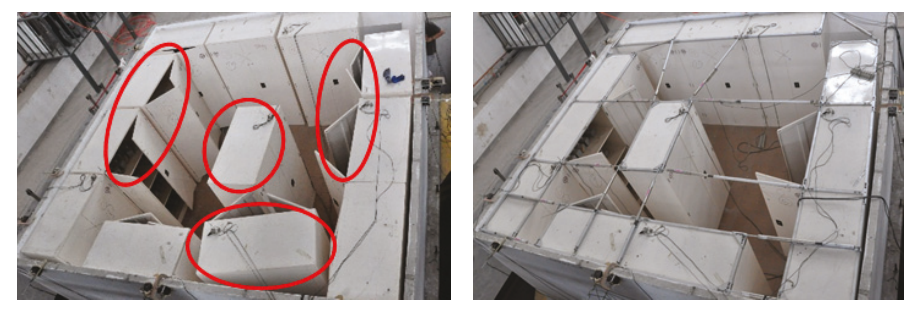

(f) Layout B-PGA $0.62 \mathrm{~g}$

FIGURE 15: Test phenomenon comparison (left: without control; right: with control). 

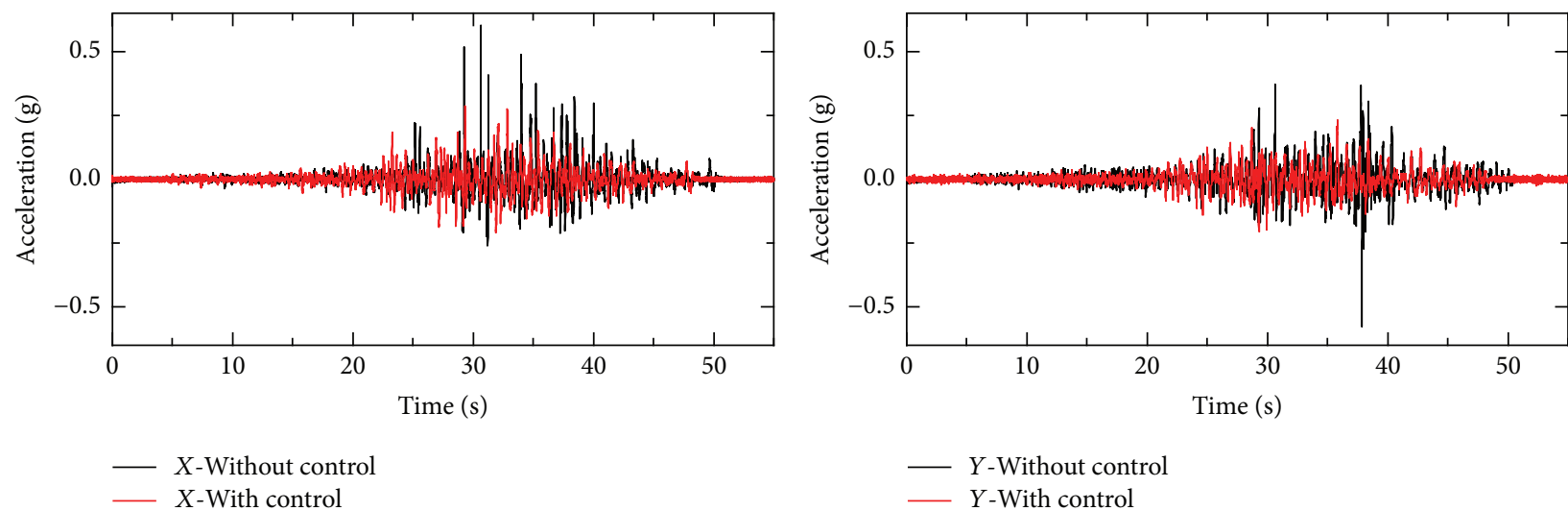

Figure 16: Acceleration time history curves of 4\# cabinet in layout A-T02 (0.20 g) (experimental).
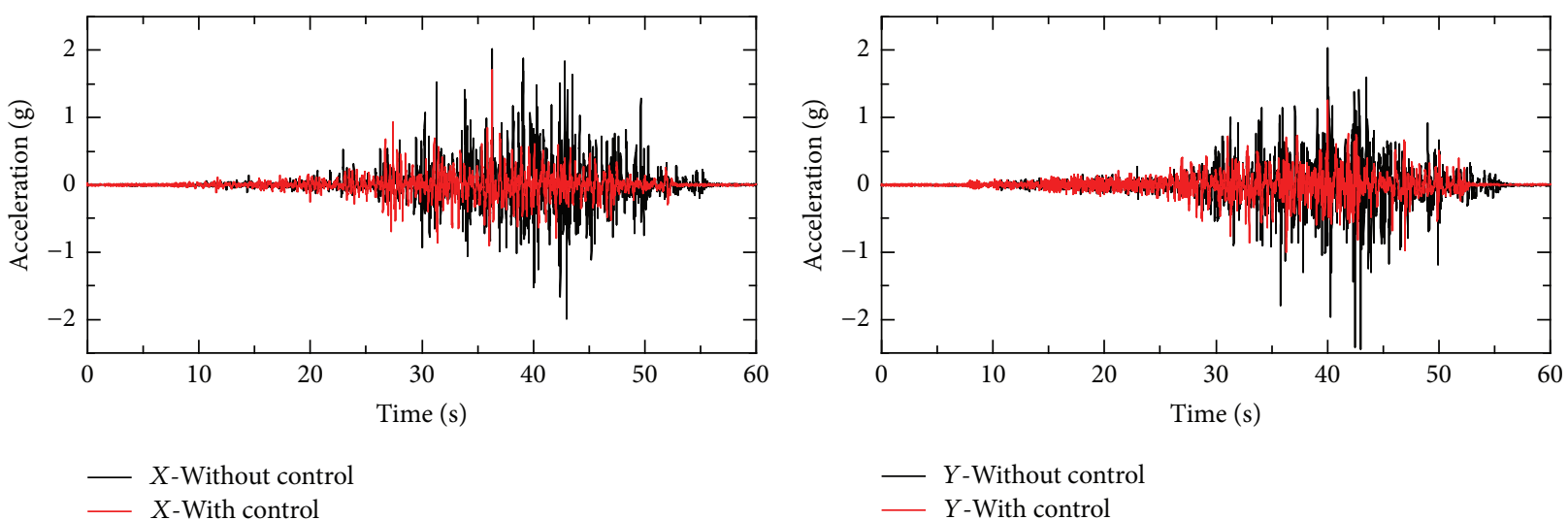

Figure 17: Acceleration time history curves of 4\# cabinet in layout A-T08 (0.62 g) (experimental).
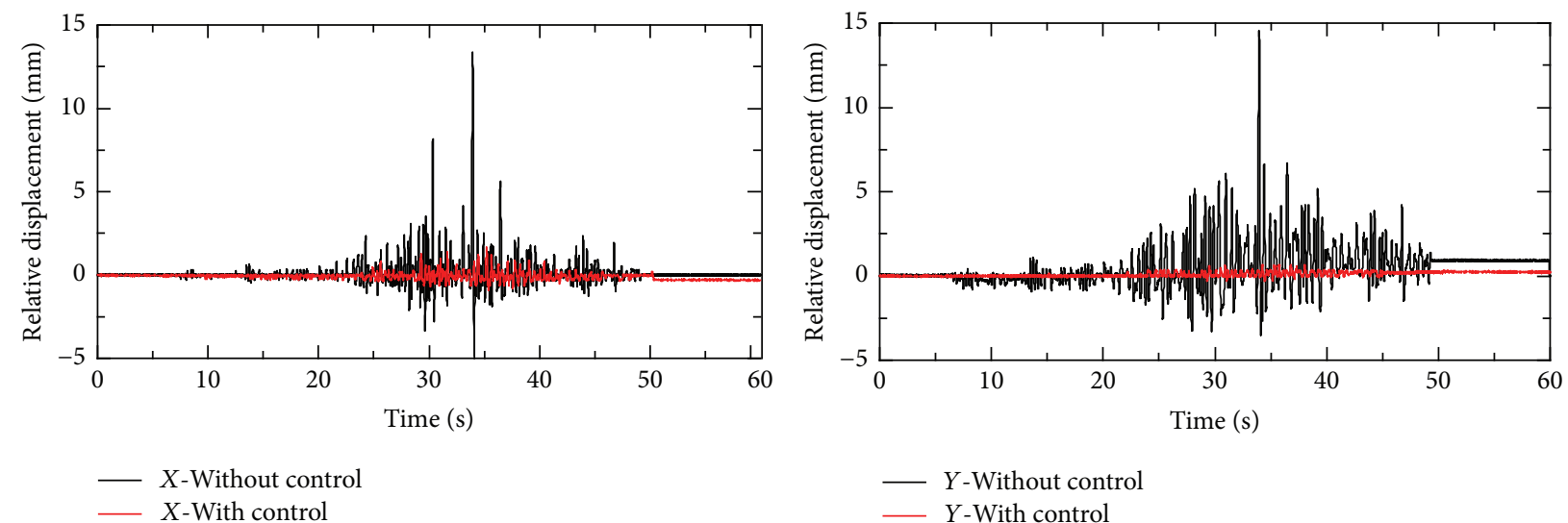

FIGURE 18: Displacement time history curves of 12\# cabinet in layout B-T02 (0.20 g) (experimental).

displacement time history curves are shown in Figures 18 and 19.

5.2.4. Damper Force and Damper Displacement Responses. The force and displacement of each damper in layout $\mathrm{A}$ and layout B are shown in Tables 7 and 8. Taking 1\# damper as an example, under T08 $(0.62 \mathrm{~g})$ level, the force and relative displacement time history curves of $1 \#$ damper are shown in Figures 20 and 21.
The results show that, under all conditions, the values of damper forces are in the range of $0.1 \mathrm{kN}$ to $2.4 \mathrm{kN}$, and the values of relative displacements are in the range of $0.1 \mathrm{~mm}$ to $10 \mathrm{~mm}$, which do not exceed the max force and total stroke of the damper. When the input PGA is small, damper force is relatively small, with no obvious damping effect. When the input PGA increases, damper force also increases, which can give full play to the damping effect of the damper. 
TABLE 7: Force and displacement of each damper in layout A (experimental).

\begin{tabular}{|c|c|c|c|c|c|c|}
\hline Input levels & $\begin{array}{c}\text { 1\# damper } \\
\text { Force } / \mathrm{kN}\end{array}$ & $\begin{array}{c}\text { 2\# damper } \\
\text { Force/kN }\end{array}$ & $\begin{array}{c}\text { 3\# damper } \\
\text { Force/kN }\end{array}$ & $\begin{array}{c}\text { 1\# damper } \\
\text { Displacement } / \mathrm{mm}\end{array}$ & $\begin{array}{c}\text { 2\# damper } \\
\text { Displacement } / \mathrm{mm}\end{array}$ & $\begin{array}{c}\text { 3\# damper } \\
\text { Displacement } / \mathrm{mm}\end{array}$ \\
\hline T01 $(0.20 \mathrm{~g})$ & 0.32 & 0.09 & 0.13 & 0.07 & 1 & 0.15 \\
\hline T02 (0.20 g) & 0.34 & 0.06 & 0.08 & 0.07 & l & 0.04 \\
\hline T03 (0.20 g) & 0.28 & 0.11 & 0.13 & 0.06 & 1 & 0.15 \\
\hline T04 (0.40 g) & 0.85 & 0.20 & 0.41 & 0.17 & I & 0.34 \\
\hline T05 (0.40 g) & 0.96 & 0.18 & 0.13 & 0.32 & I & 0.14 \\
\hline T06 (0.40 g) & 0.58 & 0.22 & 0.26 & 0.24 & l & 0.23 \\
\hline T07 (0.20 g) & 2.23 & 0.99 & 1.09 & 1.61 & 1 & 0.60 \\
\hline T08 (0.62 g) & 2.39 & 0.74 & 1.04 & 2.69 & I & 0.99 \\
\hline T09 $(0.62 \mathrm{~g})$ & 0.81 & 0.61 & 0.32 & 0.38 & l & 1.27 \\
\hline
\end{tabular}

Note. The data missing of 2\# damper's displacement is due to the damage of measuring instrument during the test.

TABLE 8: Force and displacement of each damper in layout B (experimental).

\begin{tabular}{lcccccc}
\hline Input levels & $\begin{array}{c}\text { 1\# damper } \\
\text { Force/kN }\end{array}$ & $\begin{array}{c}\text { 2\# damper } \\
\text { Force/kN }\end{array}$ & $\begin{array}{c}\text { 3\# damper } \\
\text { Force/kN }\end{array}$ & $\begin{array}{c}\text { 1\# damper } \\
\text { Displacement/mm }\end{array}$ & $\begin{array}{c}\text { 2\# damper } \\
\text { Displacement/mm }\end{array}$ & $\begin{array}{c}\text { 3\# damper } \\
\text { Displacement/mm }\end{array}$ \\
\hline T01 $(0.20 \mathrm{~g})$ & 0.47 & 0.28 & 0.10 & 0.65 & 0.61 & 0.13 \\
T02 $(0.20 \mathrm{~g})$ & 0.43 & 0.23 & 0.08 & 0.45 & 1.14 & 0.20 \\
T03 $(0.20 \mathrm{~g})$ & 0.53 & 0.30 & 0.12 & 3.99 & 1.58 & 0.18 \\
\hline T04 $(0.40 \mathrm{~g})$ & 1.35 & 0.75 & 0.86 & 3.62 & 1.81 & 0.76 \\
T05 $(0.40 \mathrm{~g})$ & 0.80 & 0.31 & 0.27 & 1.07 & 2.26 & 0.78 \\
T06 $(0.40 \mathrm{~g})$ & 0.54 & 0.58 & 0.74 & 6.32 & 2.75 & 2.51 \\
\hline T07 $(0.20 \mathrm{~g})$ & 1.66 & 0.89 & 1.37 & 5.46 & 2.31 & 1.18 \\
T08 $(0.62 \mathrm{~g})$ & 2.26 & 0.79 & 0.83 & 9.29 & & 2.07 \\
T09 $(0.62 \mathrm{~g})$ & 1.11 & 0.97 & 0.74 & & & \\
\hline
\end{tabular}

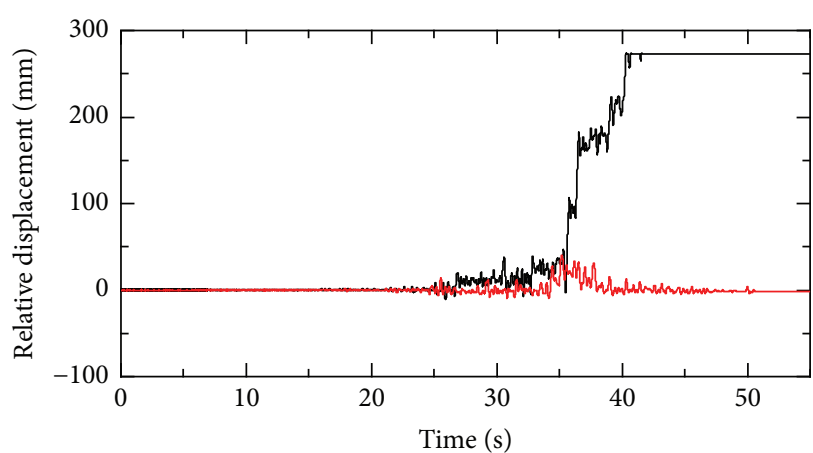

$X$-Without control

- X-With control

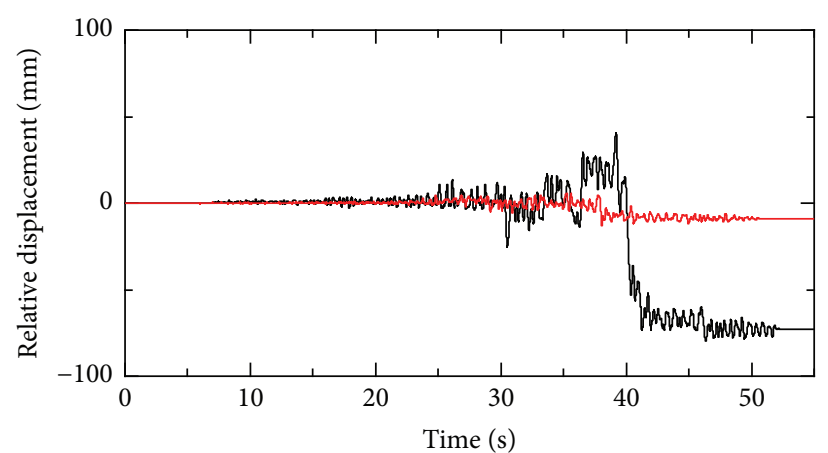

- Y-Without control

- Y-With control

FIGURE 19: Displacement time history curves of 12\# cabinet in layout B-T08 (0.62 g) (experimental).

5.2.5. Acceleration Amplification Factor of Relic Cabinets. The acceleration amplification factor of relic cabinet $\gamma$ can be defined as the ratio of the peak acceleration of cabinet top and the peak acceleration of input, seen in (3), which can reflect the acceleration amplification effect of relic cabinets under earthquake motions. The average acceleration amplification factor is the average value of all cabinets and all ground motions under certain PGA level. The average acceleration amplification factors with and without control under different PGA levels are shown in Figures 22 and 23.

The results show that, without control, the acceleration amplification effect is very obvious, and the acceleration amplification factor increases with the increase of the input PGA. However, with control, the acceleration amplification factor of the cabinet is obviously reduced. Besides, compared with the two layouts, after installing the damping device, the 


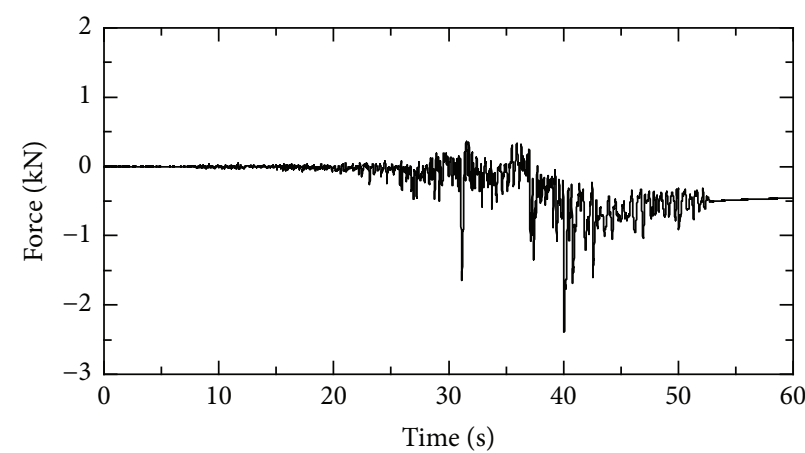

— Damper force

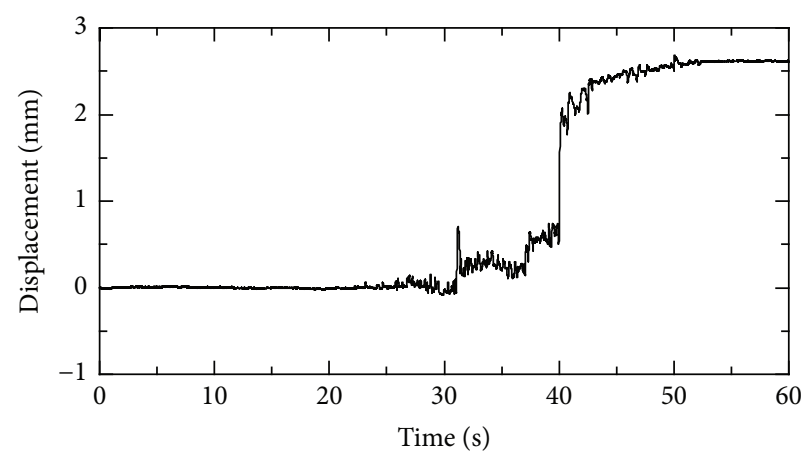

— Damper displacement

FIgURE 20: Force and relative displacement time history curves of $1 \#$ damper in layout A (experimental).

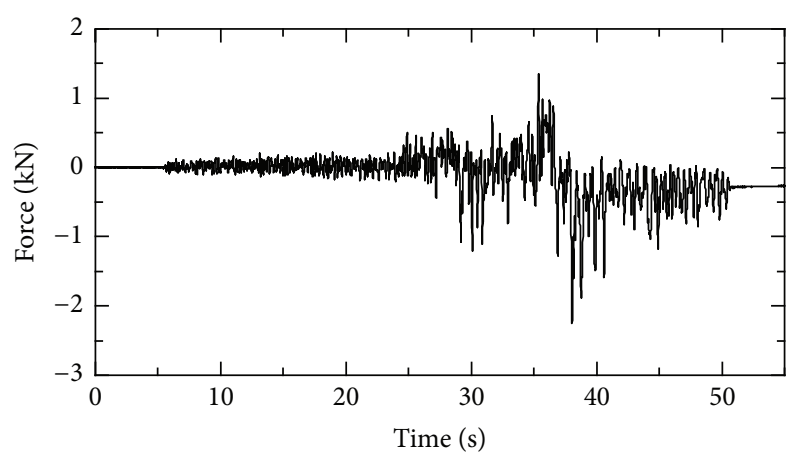

- Damper force

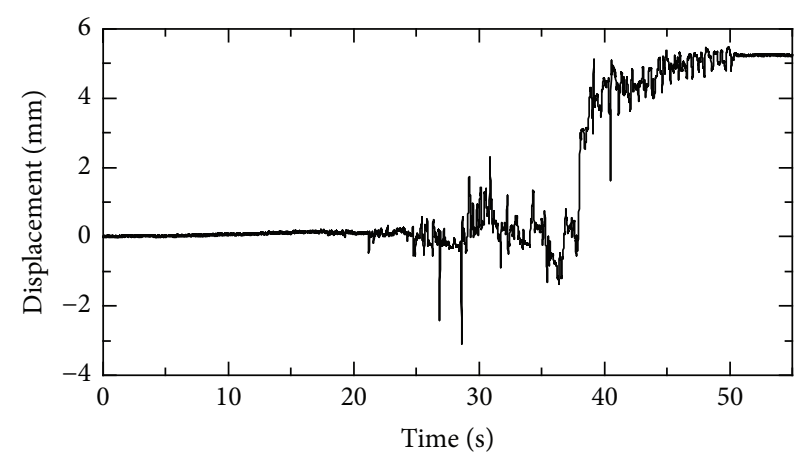

- Damper displacement

FIGURE 21: Force and relative displacement time history curves of 1\# damper in layout B (experimental).

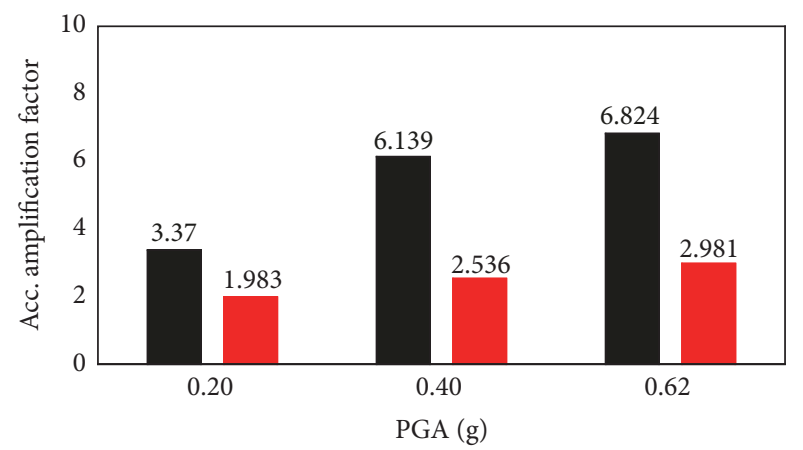

$X$-Without control

$X$-With control

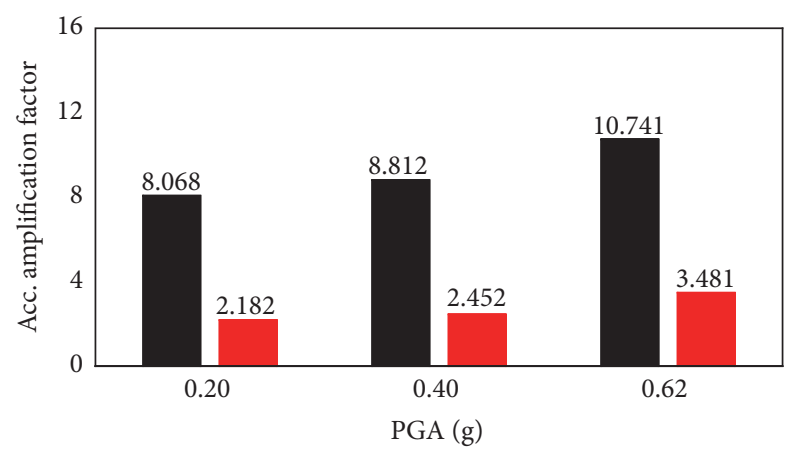

$Y$-Without control

$Y$-With control

FIGURE 22: Average acceleration amplification factor of relic cabinets in layout A (experimental).

acceleration amplification factor of the layout $\mathrm{A}$ decreases more, and the damping effect of layout $\mathrm{A}$ is better than that of layout $\mathrm{B}$.

$$
\gamma=\frac{\text { peak acceleration of cabinet top }}{\text { peak acceleration of input }}
$$$$
\text { average } \gamma=\frac{1}{3} \sum_{j=1}^{1}\left(\frac{1}{n} \sum_{i=1}^{n} \gamma_{\text {cabinet }_{i}}\right)_{\text {motion }_{j}} \text {. }
$$

5.2.6. Acceleration Damping Ratio and Displacement Damping Ratio of Relic Cabinets. The acceleration damping ratio and displacement damping ratio of relic cabinets are defined correspondingly to the numerical simulation section, seen in Section 4. The average damping ratio under certain PGA level can be calculated by (4), which is the average value of all cabinets and all ground motions under this PGA level. The average acceleration and displacement damping ratios under different PGA levels are shown in Table 9. 
TABLE 9: Average acceleration and displacement damping ratios of relic cabinets (experimental).

\begin{tabular}{|c|c|c|c|c|c|}
\hline & \multirow{2}{*}{ Input PGA levels } & \multicolumn{2}{|c|}{ Average $\alpha$} & \multicolumn{2}{|c|}{ Average $\beta$} \\
\hline & & $X$ & $Y$ & $X$ & $Y$ \\
\hline \multirow{4}{*}{ Layout A } & $0.20 \mathrm{~g}$ & 0.67 & 0.61 & 0.67 & 0.96 \\
\hline & $0.40 \mathrm{~g}$ & 0.50 & 0.37 & 0.56 & 0.34 \\
\hline & $0.62 \mathrm{~g}$ & 0.58 & 0.45 & 0.58 & 0.35 \\
\hline & Average & 0.58 & 0.48 & 0.60 & 0.55 \\
\hline \multirow{5}{*}{ Layout B } & $0.20 \mathrm{~g}$ & 0.73 & 0.78 & 0.38 & 0.34 \\
\hline & $0.40 \mathrm{~g}$ & 0.72 & 0.62 & 0.57 & 0.51 \\
\hline & $0.62 \mathrm{~g}$ & 0.75 & 0.79 & 0.50 & 0.42 \\
\hline & Average & 0.73 & 0.73 & 0.48 & 0.42 \\
\hline & Total average & \multicolumn{2}{|c|}{0.63} & \multicolumn{2}{|c|}{0.51} \\
\hline
\end{tabular}

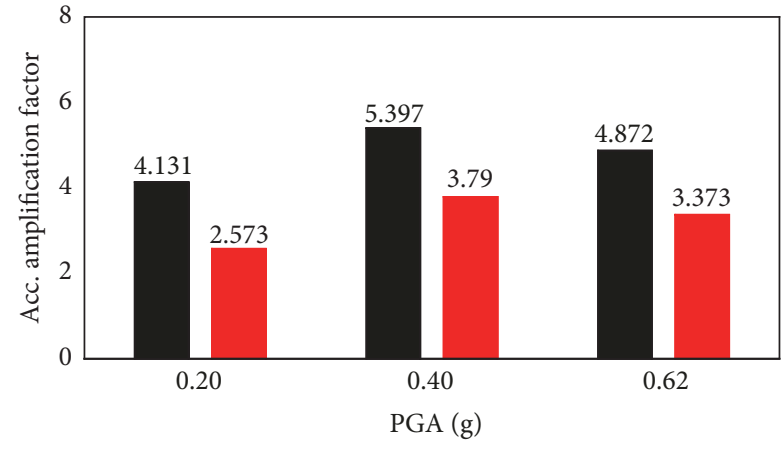

$X$-Without control
$X$-With control

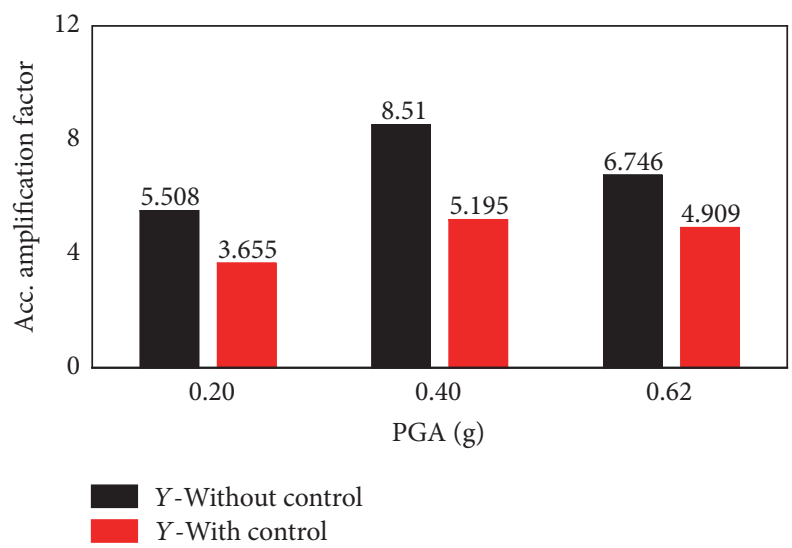

FIGURE 23: Average acceleration amplification factor of relic cabinets in layout B (experimental).

The results show that the optimal acceleration damping ratio is 0.13 and the total average acceleration damping ratio is 0.63 ; the optimal displacement damping ratio is 0.01 and the total average displacement damping ratio is 0.51 . The designed damping device performs obvious damping effect both in acceleration and displacement responses, which totally achieves the expected purpose of relic protection:

$$
\begin{aligned}
& \text { average } \alpha=\frac{1}{3} \sum_{j=1}^{3}\left(\frac{1}{n} \sum_{i=1}^{n} \alpha_{\text {cabinet }_{i}}\right)_{\text {motion }_{j}}, \\
& \text { average } \beta=\frac{1}{3} \sum_{j=1}^{3}\left(\frac{1}{n} \sum_{i=1}^{n} \beta_{\text {cabinet }_{i}}\right)_{\text {motion }_{j}} .
\end{aligned}
$$

\section{Conclusions}

Due to the fact that almost no damping and isolation measure has been taken in most relic cabinets, the seismic risk of relic cabinets and the inside relics is very high. Corresponding study of the damping methods is urgently needed. There are many difficulties in the damping design of relic cabinets. Firstly, it is necessary to ensure the durability of the dampers and connections, which cannot be damaged for a long time and can maintain the working condition. Secondly, toxic and harmful gases and liquids should not be produced to avoid damaging the environment in the storehouse. Thirdly, when designing the connecting elements, it is important to ensure that the modular assembly method can be used without moving the relic cabinets, drilling holes, or using glue, which may damage the cabinets. At the same time, the construction should be simple and fast, so as to minimize the disturbance to the storage environment.

In order to solve these problems, a modular assembly damping device is designed with silicone damper as the key part. The finite element model is established and analyzed to determine the damper parameters, and through the shaking table tests it is proved that the damping device can effectively reduce relic cabinets' acceleration and displacement responses under earthquakes, to achieve the purpose of relics protection.

The designed damping device has obvious damping effect and can effectively improve the seismic performance of the cultural relics. Meanwhile, the advantages of the device are as follows: the installation is simple and fast, with no need to move the relics in the cabinets and the minimal effect on the storehouse; the use of the top space of the cabinet does not affect daily work; it uses environmental protection material which is dust free with no vibration and no pollution; it is mechanically designed, passive damping, and maintenancefree; all the components can be manufactured in batches and connected only with bolts. As the adjustable components, the 
generalizability of the proposed damping method to another close situation is also good.

In conclusion, through numerical simulation and shaking table tests, the effectiveness of the modular damping method is demonstrated. Supreme seismic effectiveness and practical operability are proved. A positive reference for future study on seismic protection of cabinet stored cultural relics is offered.

\section{Conflicts of Interest}

The authors declare that there are no conflicts of interest regarding the publication of this paper.

\section{Acknowledgments}

The authors appreciate the financial support from the Basic Research Foundation of Institute of Engineering Mechanics, CEA (2017A01), the Earthquake Scientific Research Funds Program (201508023), and Program for Innovative Research Team in China Earthquake Administration.

\section{References}

[1] C. C. Spyrakos, C. A. Maniatakis, and I. M. Taflampas, "Application of predictive models to assess failure of museum artifacts under seismic loads," Journal of Cultural Heritage, vol. 23, pp. 11-21, 2017.

[2] M.-T. Gong, Q. Wei, P.-L. Feng, Z.-J. Zhang, and J. Yang, "Survey on the damaged levels of the movable cultural relics and buildings during the 5.12 wenchuan earthquake in sichuan province," Sciences of Conservation and Archaeology, vol. 28, no. 4, pp. 40-47, 2016 (Chinese).

[3] T. Neurohr and G. McClure, "Shake table testing of museum display cases," Canadian Journal of Civil Engineering, vol. 35, no. 12, pp. 1353-1364, 2008.

[4] K. Yusuke, I. Kazuyuki, and T. Kenzo, "Use of adhesive mats to protect cultural properties from fall down during earthquakes," Proc of Urban Cultural Heritage Disaster Mitigation, vol. 2, pp. 85-90, 2008.

[5] B. Myslimaj, S. Gamble, D. Chin-Quee et al., "Base isolation technologies for seismic protection of museum artifacts," Quee, 2003.

[6] Q. Zhou, W. M. Yan, and J. B. Ji, "Experimental study on aseismic behaviors of a free-standing cultural relic supported by traditional methods," Sciences of Conservation and Archaeology, vol. 27, no. 2, pp. 63-72, 2015 (Chinese).

[7] I. Caliò and M. Marletta, "Passive control of the seismic rocking response of art objects," Engineering Structures, vol. 25, no. 8, pp. 1009-1018, 2003.

[8] FEMA, FEMA E-74: Reducing the Risks of Nonstructural Earthquake Damage - A Practical Guide, 2012.

[9] L. Berto, T. Favaretto, and A. Saetta, "Seismic risk mitigation technique for art objects: Experimental evaluation and numerical modelling of double concave curved surface sliders," Bulletin of Earthquake Engineering, vol. 11, no. 5, pp. 1817-1840, 2013.

[10] J. Podany, "An overview of seismic damage mitigation for museums," in Proceedings of the International Symposium on Advances of Protection Devices for Museum Exhibits, Beijing, China, 2015.
[11] D. Konstantinidis and N. Makris, "Experimental and analytical studies on the response of freestanding laboratory equipment to earthquake shaking," Earthquake Engineering \& Structural Dynamics, vol. 38, no. 6, pp. 827-848, 2009.

[12] E. Cosenza, L. Di Sarno, G. Maddaloni, G. Magliulo, C. Petrone, and A. Prota, "Shake table tests for the seismic fragility evaluation of hospital rooms," Earthquake Engineering \& Structural Dynamics, vol. 44, no. 1, pp. 23-40, 2015.

[13] L. Di Sarno, C. Petrone, G. Magliulo, and G. Manfredi, "Dynamic properties of typical consultation room medical components," Engineering Structures, vol. 100, pp. 442-454, 2015.

[14] C. E. Wittich and T. C. Hutchinson, "Shake table tests of unattached, asymmetric, dual-body systems," Earthquake Engineering \& Structural Dynamics, vol. 46, no. 9, pp. 1391-1410, 2017.

[15] C. Petrone, L. Di Sarno, G. Magliulo, and E. Cosenza, "Numerical modelling and fragility assessment of typical freestanding building contents," Bulletin of Earthquake Engineering, vol. 15, no. 4, pp. 1609-1633, 2017.

[16] M. Martinez-Rodrigo and M. L. Romero, "An optimum retrofit strategy for moment resisting frames with nonlinear viscous dampers for seismic applications," Engineering Structures, vol. 25, no. 7, pp. 913-925, 2003.

[17] H. Zhou and J. Grimble, Test Report for SP24235 and SP25668 Fluid Viscous Damping Device, ITT Enidine Test Lab, 2017.

[18] D. L. García, "A simple method for the design of optimal damper configurations in MDOF structures," Earthquake Spectra, vol. 17, no. 3, pp. 387-398, 2001.

[19] Z.-D. Xu, Y.-P. Shen, and H.-T. Zhao, "A synthetic optimization analysis method on structures with viscoelastic dampers," Soil Dynamics and Earthquake Engineering, vol. 23, no. 8, pp. 683689, 2003.

[20] M. P. Singh and L. M. Moreschi, "Optimal placement of dampers for passive response control," Earthquake Engineering \& Structural Dynamics, vol. 31, no. 4, pp. 955-976, 2002.

[21] L. M. Zhu, Seismic Control and Optimization Design of LargeSpan Space Structures with Viscous Dampers, China Academy of Building Research, 2007.

[22] GB50011-2010, Code for Seismic Design of Buildings, 2010 (Chinese). 


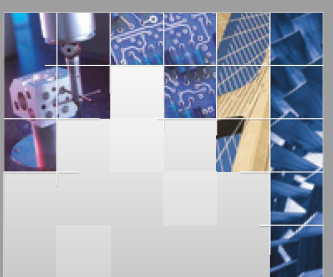

\section{Enfincering}
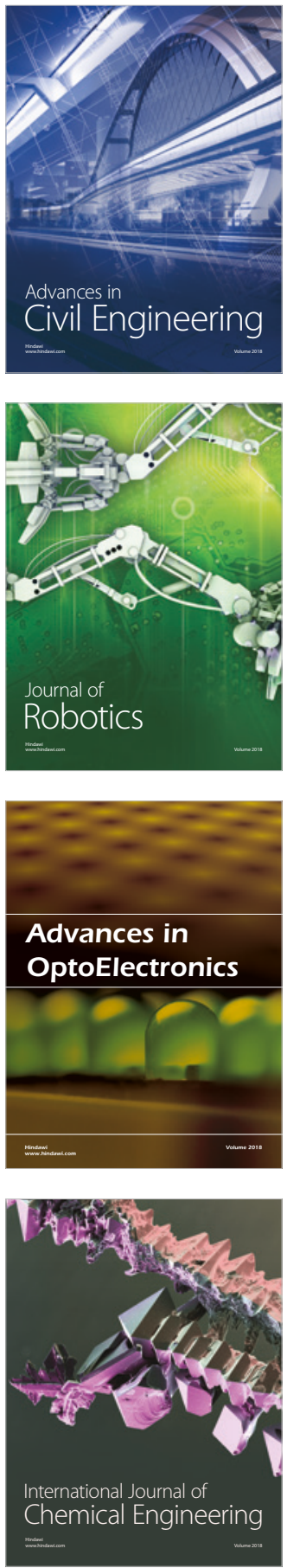

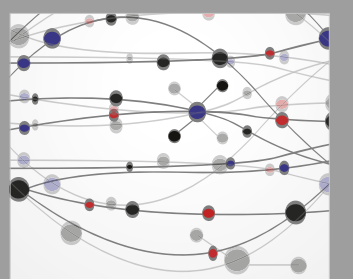

\section{Rotating \\ Machinery}

The Scientific World Journal

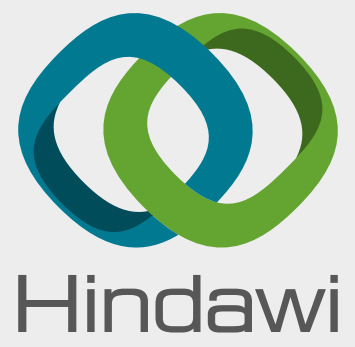

Submit your manuscripts at

www.hindawi.com
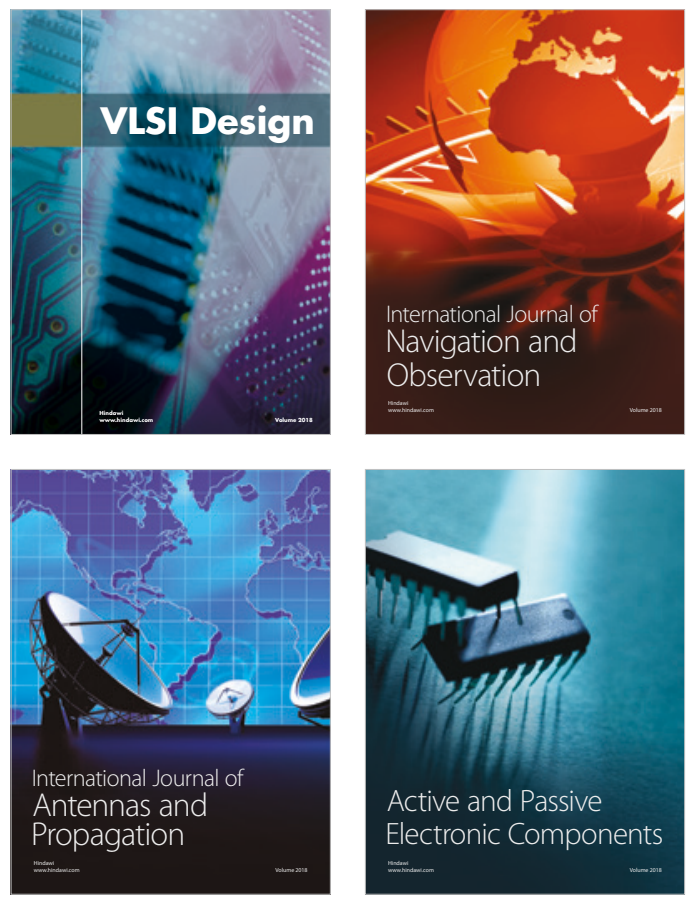
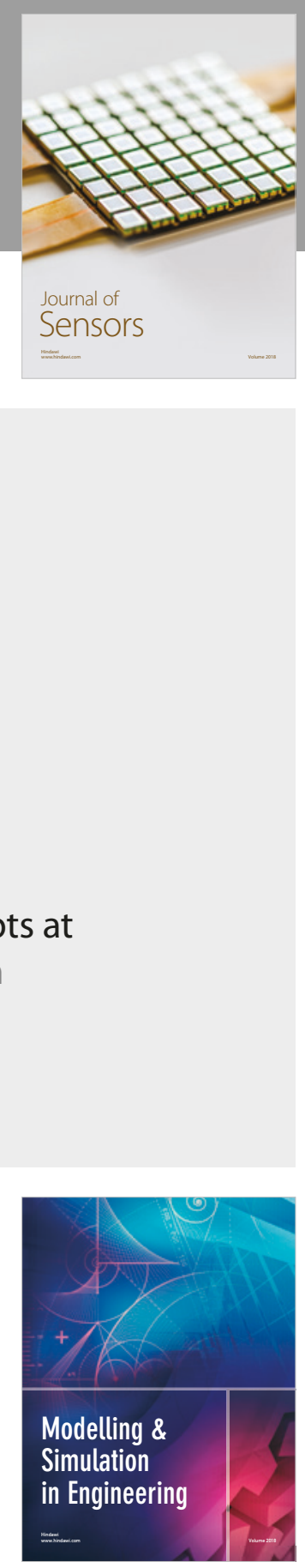

\section{Advances \\ Multimedia}
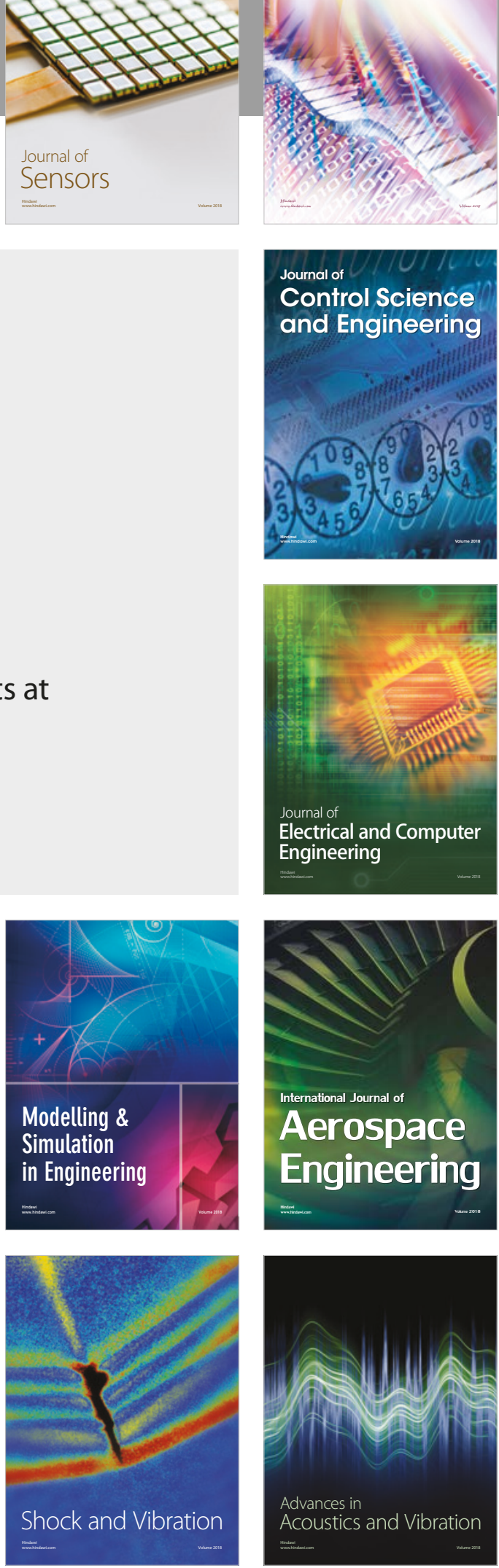